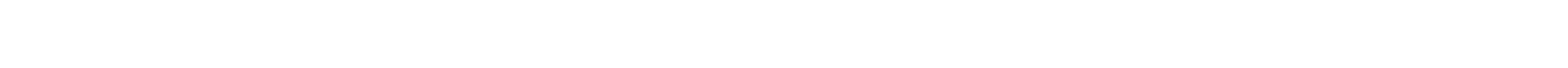

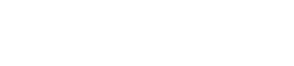 \\ قبم علوم الحيلة/كلية العلوم/جلمعة الموصل \\ فليهة حبيب مسبن \\ كلية الطب/جلمعة نينوى
}

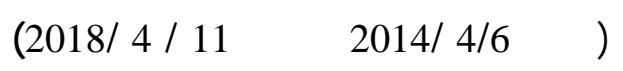

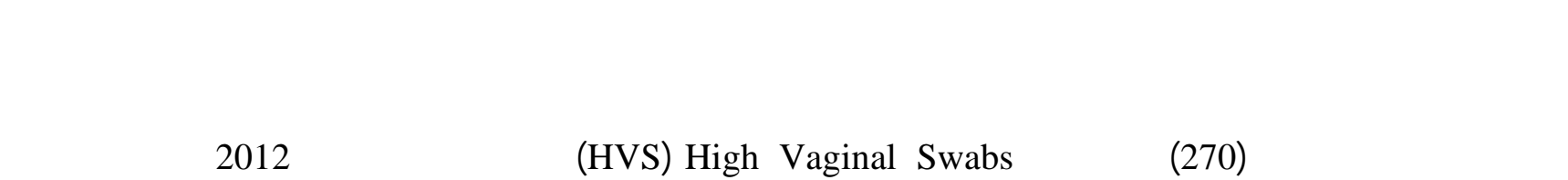

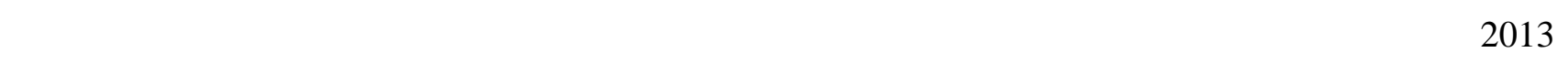
الرهم.

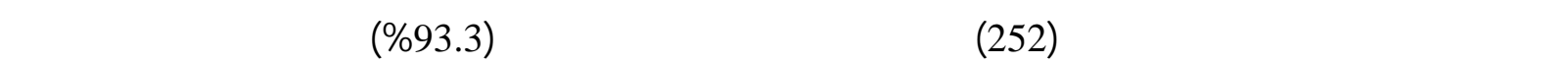

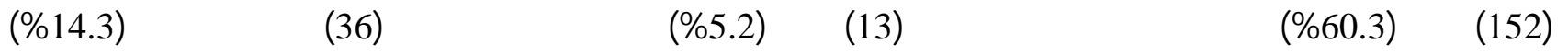

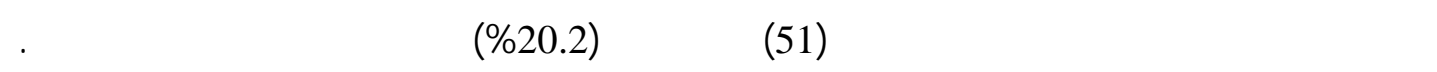

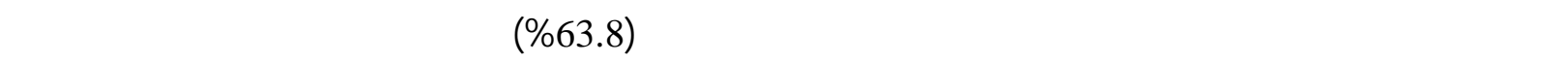

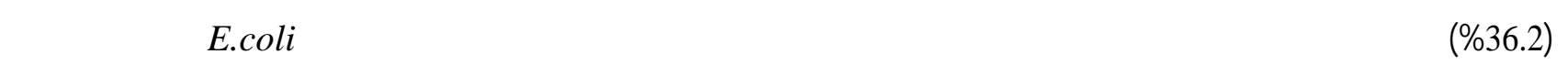

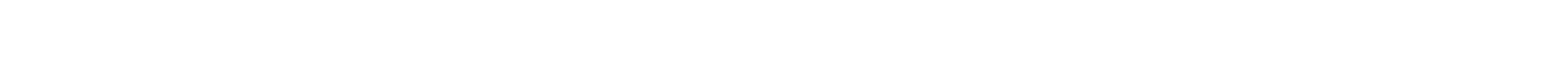
مفردة أو مشتركة مع البكتريا.

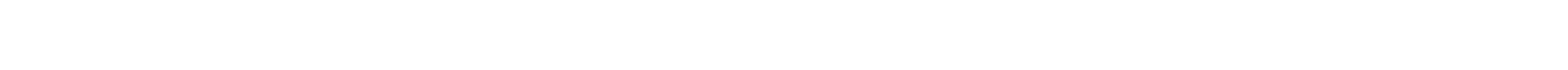

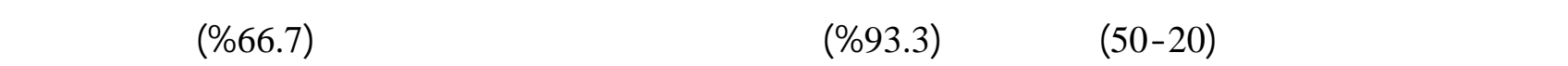

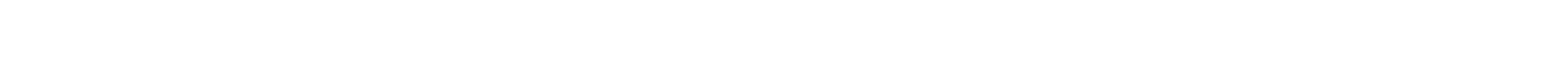
المدروسة. الكالت الدالة: التهابت المهل، عق الرهم، عولمل النطورة.

\section{Isolation and Identification of some Microorganisms Causing Vaginitis and Cervicitis and Relationship of Risk Factors with these Infections}

Faleeha H. Hussein

College of Medicine/

University of Nineveh
Muhsin A. Essa

Department of Biology/College of Science

University of Mosul

\section{ABSTRACT}

This research was performed to isolate and identify the Microorganisms causing vaginitis and cervicitis and relationship of some risk factors with these infections. Two hundred and seventy high vaginal specimens were collected during the period from December 2012 until the end of May 2013, 
from pregnant and non- pregnant women of different ages, who had the clinical symptoms of vaginitis and cervicitis infections.

Isolation and identification results showed that (252) specimen (93.3\%) were positive for microbial culture, these specimen distributed among (152) specimen (60.3\%) appeared single bacterial growth, (13) specimen (5.2\%) were mixed bacterial growth, (36) specimen (14.3\%) mixed bacterial with candida growth and (51) specimen (20.2\%) candidal growth only.

Gram positive bacteria formed the high percentage (63.8\%) compared with Gram negative bacteria (36.2\%). Staphylococcus spp. were the most isolate among Gram positive bacteria and E.coli were the most isolate among Gram negative bacteria. Candida albicans showed significant appearance among positive microbial cultures either as single or mixed with bacteria.

Results showed relationship between some risk factors with studied infections, it was found that almost all infections were in the married women, aged (20-50) years (93.3\%) and the most infections in non- pregnant women (66.7\%), in addition to the role of other diseases (such as UTI, diabetes) ,various contraceptive methods and other risk factors.

Keywords: Vaginitis, Cervicitis, Risk factors.

\section{الهقمة}

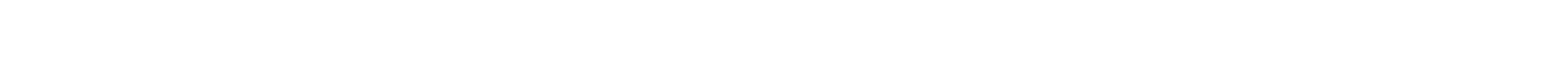

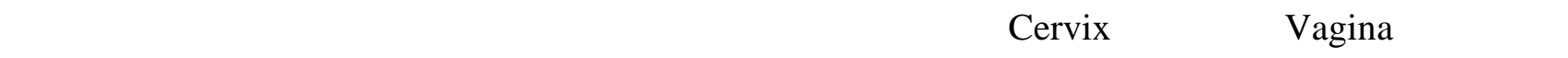

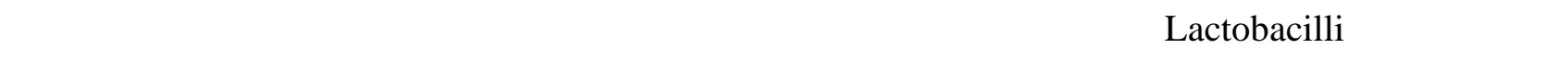

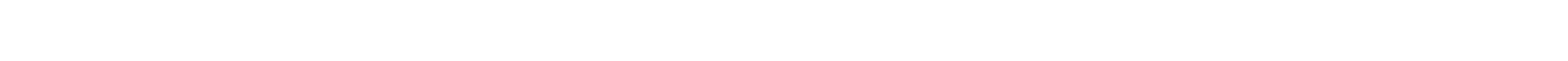

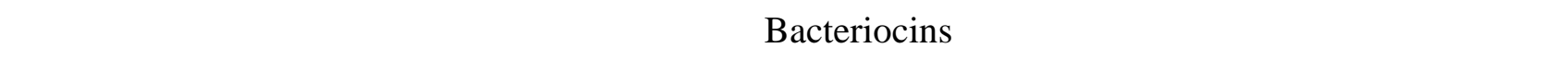
الممرضات (Curran, 2010; Hainer and Gibson, 2011). يكون الجهاز التنلسلي الأنثوي لكثر عرضة للالتهابت من الجهاز التنلسلي الذكري وذك القصر مطقة الاحليل وقرب فتحت هـ

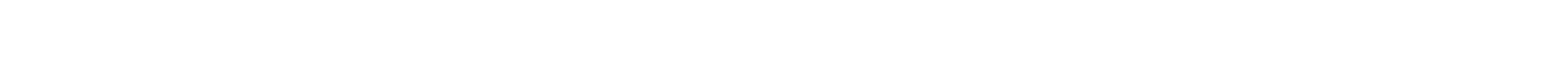
طانة الرهم في أثناء الدورة الحيضية، ووجود المتعليشك الطبيعية في الجهاز التنلسلي الأنثوي التي قد تتحول فيما بعد نتيجة تأثير الهرمونات وضعف مقاومة الجم وقلة حموضة المهبل إلى ممرضلت التتهازية (البيلتي،

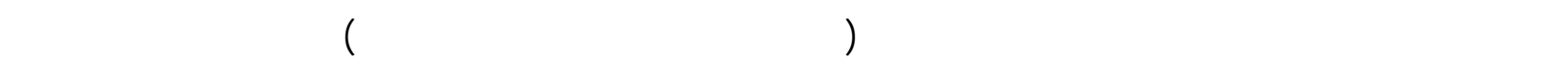

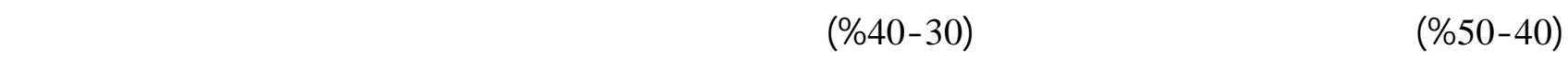

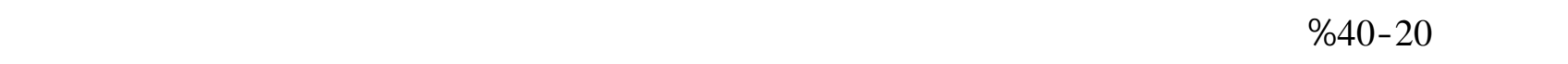

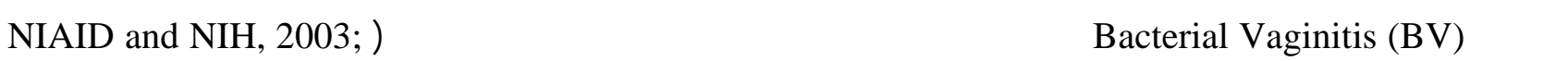

.(Koumans et al., 2007

تعد الالتهابلت التي تصيب المهل والرهم أكبر تهريد للجنين خلال فترة الحمل ذلك أن هذه الالتهابت تتسبب في عدم لكتمل

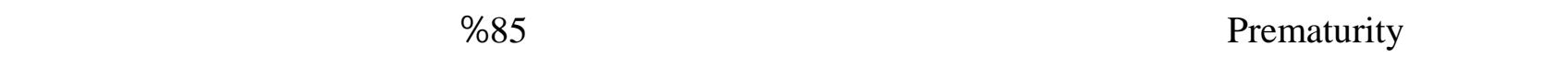

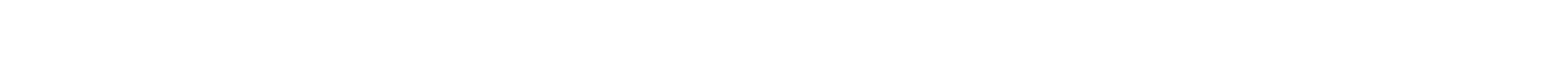
الرئيسي للإصابة بالتهابت القنة البولية UTI (Hemalatha et al., 2013). 


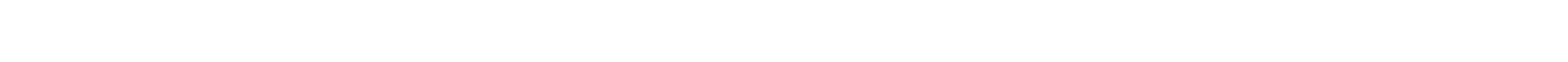

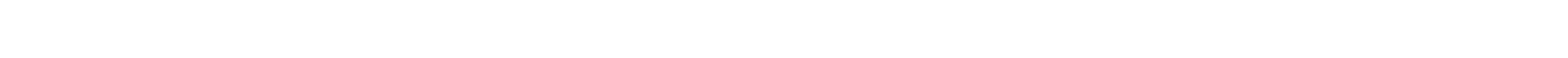

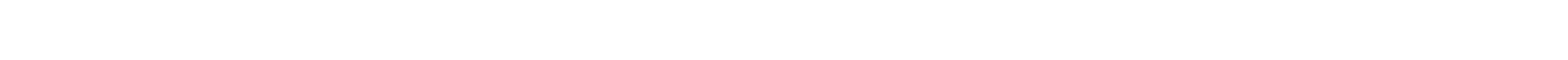

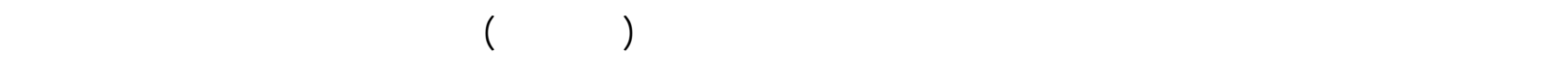

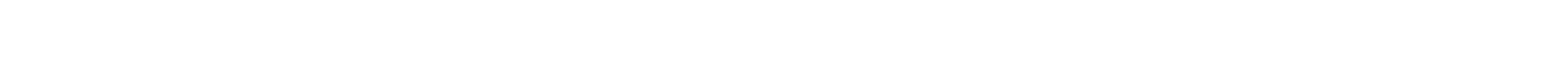

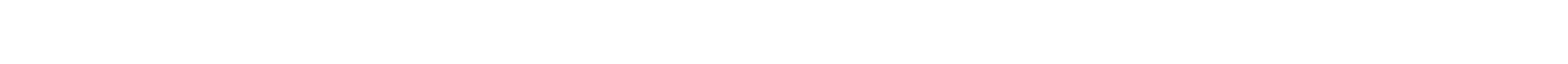

.(Hainer and Gibson, 2011)

وظرآ للانتشار الولسع لإصابت الجهاز التنلسلي الأنثوي والحلجة المستمرة في البحث عن مسبباتها وطرق اللسطررة عليها

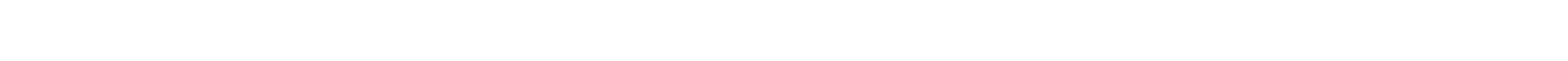

\section{المواد ولرلق المل}

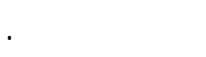

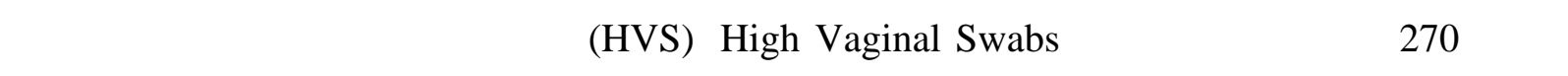

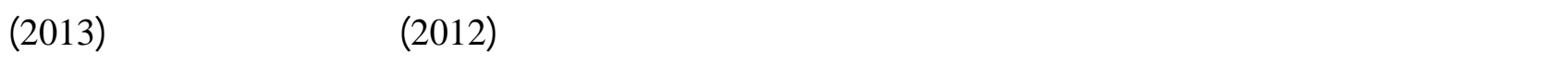

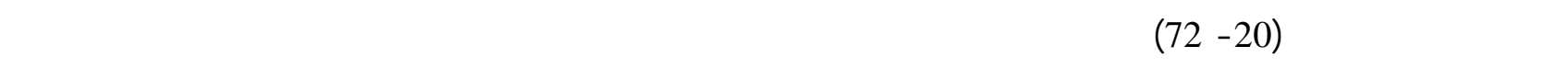

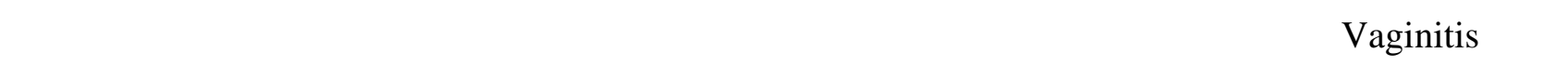

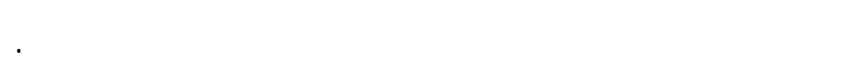

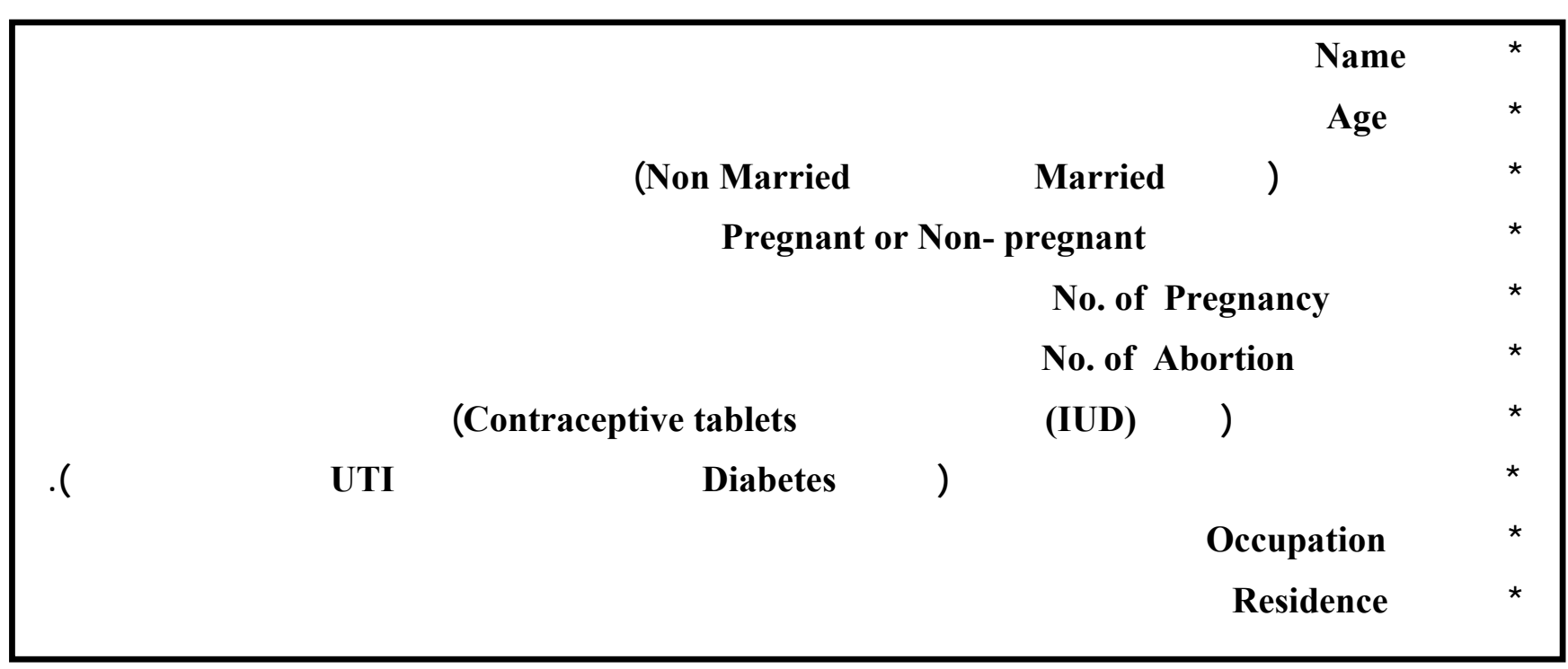




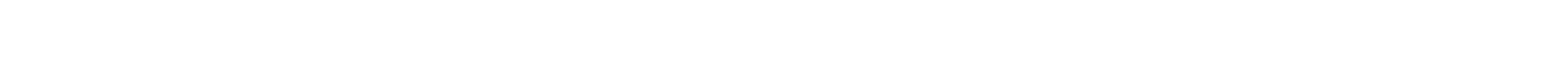

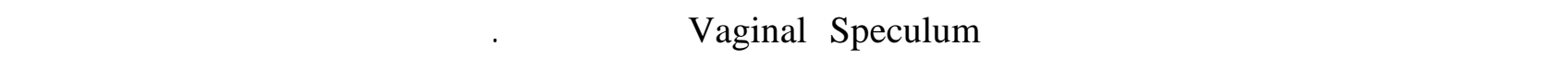
على العينت الملخونة لدعم النشخيص اللسريري الأولي (Brooks et al., 1998):

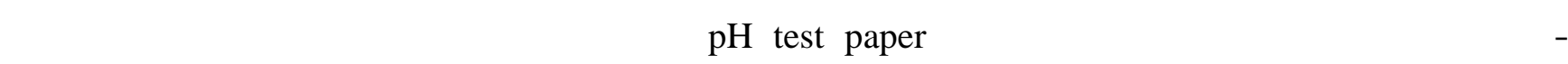

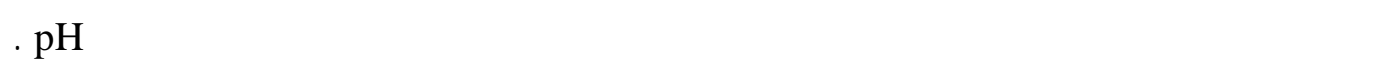

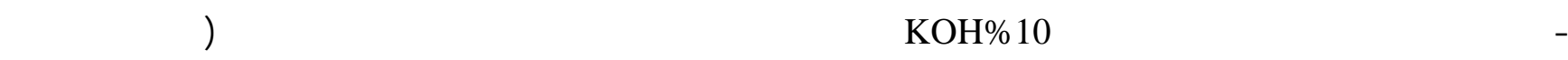
Fishy odor - حضرت مسحة من الإفرازات المهبلية علىشريحة زجلجية ظيفة و جفهت وثبت وصبغت بصبغة كرلم وفحصت تمت قوة تكبي -ر

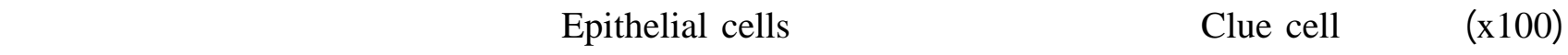

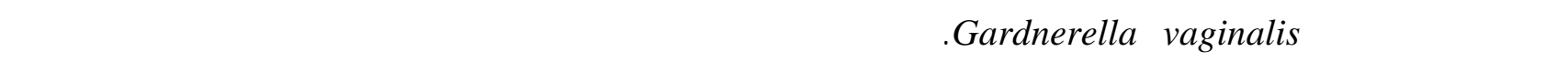
(Nugent et al., 1991) لكثر من (10) خلايا قيحية Pus cell تهمت العهة الزيتية دليل على وجود القرحلت المخطية لعنق الرحم.

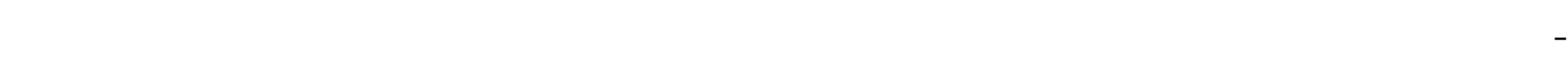
تكبير (x40) لملاظة طفيلي Trachomanas vaginalis مع الحركة الخاصة به.

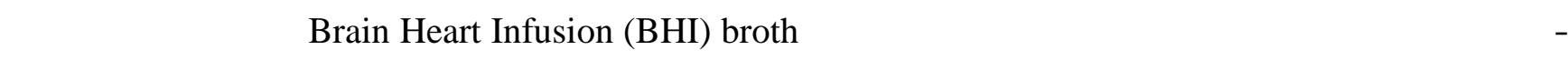

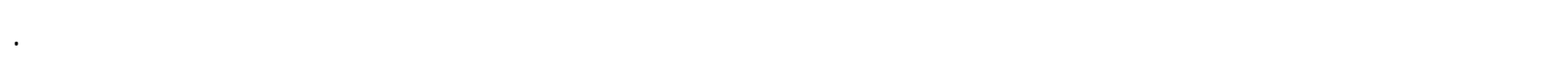

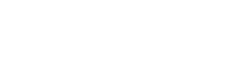

لغرض العزل الأولي لقحت العينت على الأوسط:

\section{MacConkey Agar, Blood Agar, medium SDA}

$$
\text { وحضنت هوائيً بدرجة حرارة (37)مْ ولمدة (24 - 48)ساعة. كما لقحت العينت على هذه الأوسط: }
$$

\section{Human Blood Tween Agar, MRS Agar, Columbia Blood Agar, Choclate Agar}

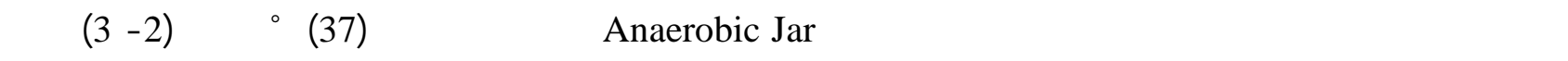
(Collee et al., 1996) بعد النتهاء فترة التحضين لجمبع الأوسط المستخمة تمت ملاظظة وتدوين الخصائص الزرعية المختلفة

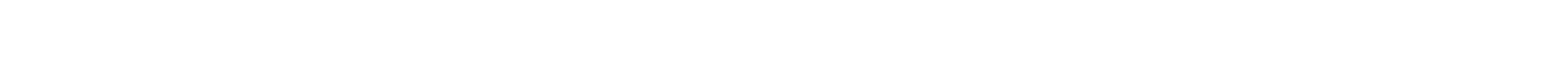

.(Atlas, 2006; Koneman et al., 2006)

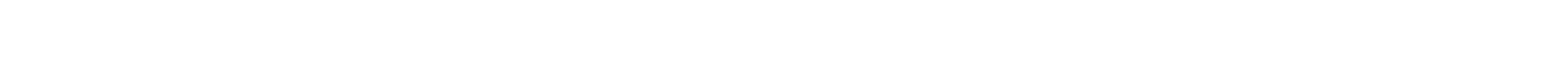

.(Konemane et al., 2006; Collee et al., 1996; Macfaddin et al., 1985 ) 
لجري هذا الاختبار بالتعاون مع مختبري مستثفى البتول ومستشف الخنساء في محلفظة نينوى لأبل تأكيد تشخيص عزلات بعض الجراثيم، ويعد هذا الظلم منطررائ التشخيص المستخمة بصورة ولسعة ولستعملت في هذا الاختبار اللثرائط المنكورة في

الجدول (1).

الجطل 1: أنواع أشوطة API المستخلمة في هذه الدرلسة

\begin{tabular}{|c|c|c|}
\hline عسب الاستخدلم & المم الشربط & ت \\
\hline Streptococcieلتشخيص اللسبحيت & Api 20 strep & 1 \\
\hline لتشخيص بعض النواع البكتريا المعوية Enterobacteriacea & Api $20 \mathrm{E}$ & 2 \\
\hline Anearobic لتشخيص البكتريا اللاهوائية & Api $20 \mathrm{~A}$ & 3 \\
\hline Staphylococci لتشخيص بكتريا المكورات العقودية & Api Staph & 4 \\
\hline لتشخيص بعض النواع الخمائر خاصة المبيضك Candida & Api Candida & 5 \\
\hline لتشخيص بكتريا الذفتيريا & Apicorany & 6 \\
\hline Haemophilus and Neisseria لتشخيص بكتريا & Api NH & 7 \\
\hline
\end{tabular}

اذ لقح المحلول الطبيعي بمستعمرة فتية وقية من الجراثيم المراد تشخيصها وبعد مزج المعلق الجرثومي جيداً، ملئت حجرات

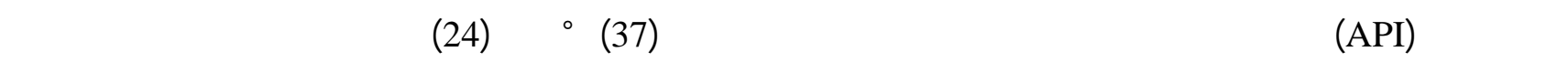
إضفة الكولثف الخاصة بكل لختبار وقورنت النتائج مع الفهرس Index المجهز من اللثركة، ليط مي لبد م الج سنس والذ ـوع

\section{Germ Tube Formation Test لختبار تكوين أنبوب الإنبات}

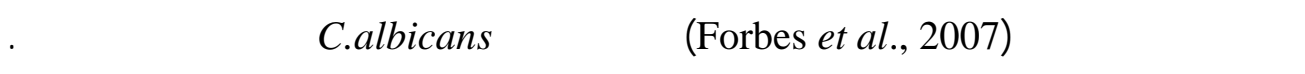

\section{النتائج والمنالثشة}

1

جمعت في هذه الدرلسة (270) عينة مهبلية من نساء حولمل (87) ونساء غير حولمل (183)، تراومت أعمارهن م ابين

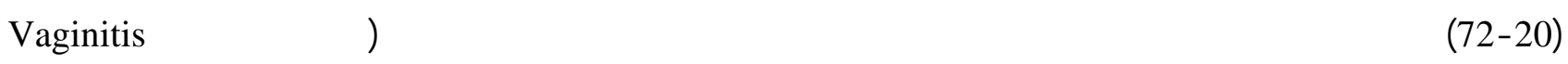

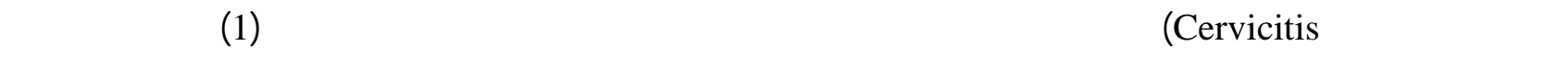
وللسالبة للزرع الجرثومي إذ كانت (252) عينة موجبة للزرع الجرثومي بنسبة (93.3\%) فيما كان عدد العينت الـ سالبة لل -زرع

(18) عينة (6.7\%).

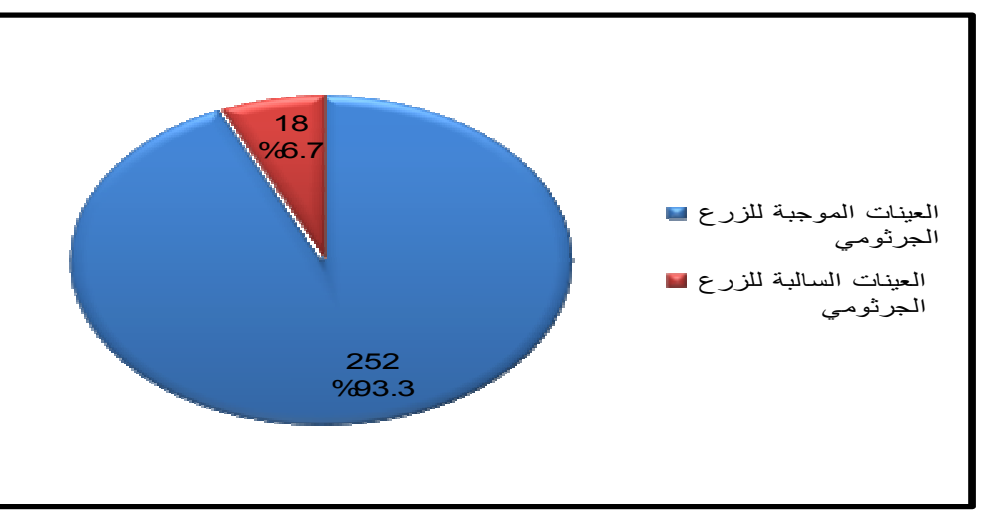




\section{الشثل 1: الأعداد والنب المئوبة للعينت الموجبة وللسالبة الزرع الجرثوصي الريلسة الحالية}

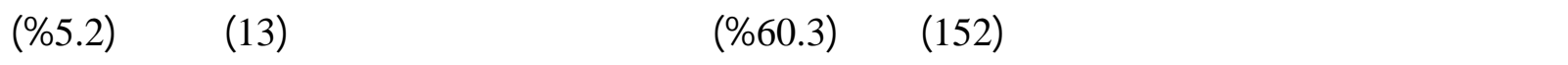

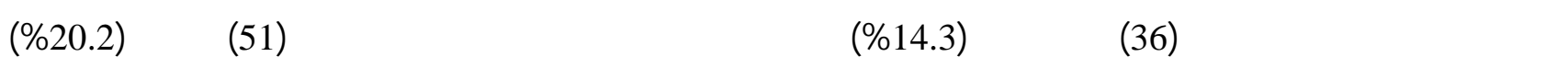

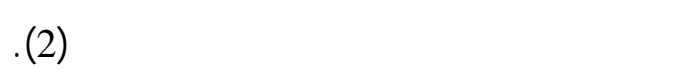
وقد يعودسبب عهم ظهور النمو في العينت للسالبة للزرع إلى لستخدلم المريضلت للمضادات الحيوية قبل لخذ العينة، على

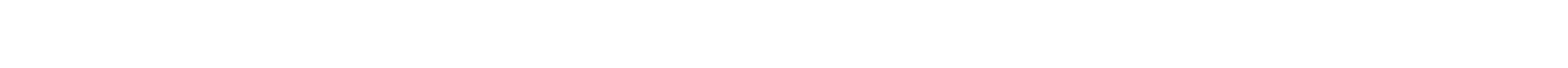

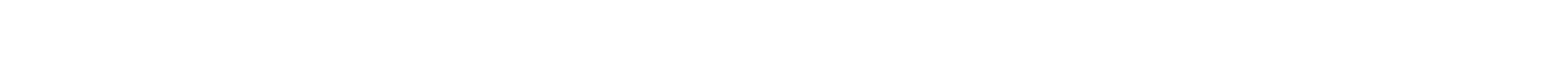

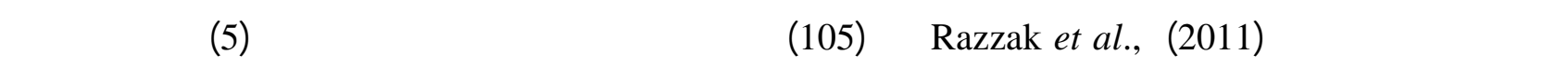

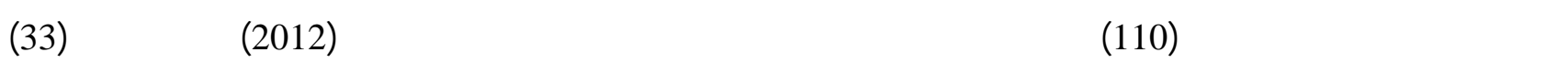

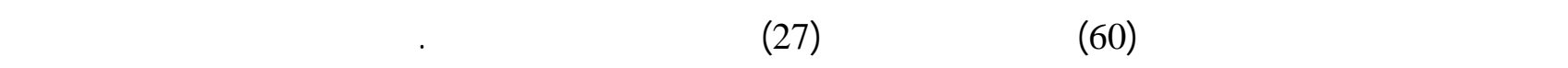
إن (63) Masood et al., (2009) لازرع البكتيري و (16) عينة موجبة للزرع الفطري (Candida).

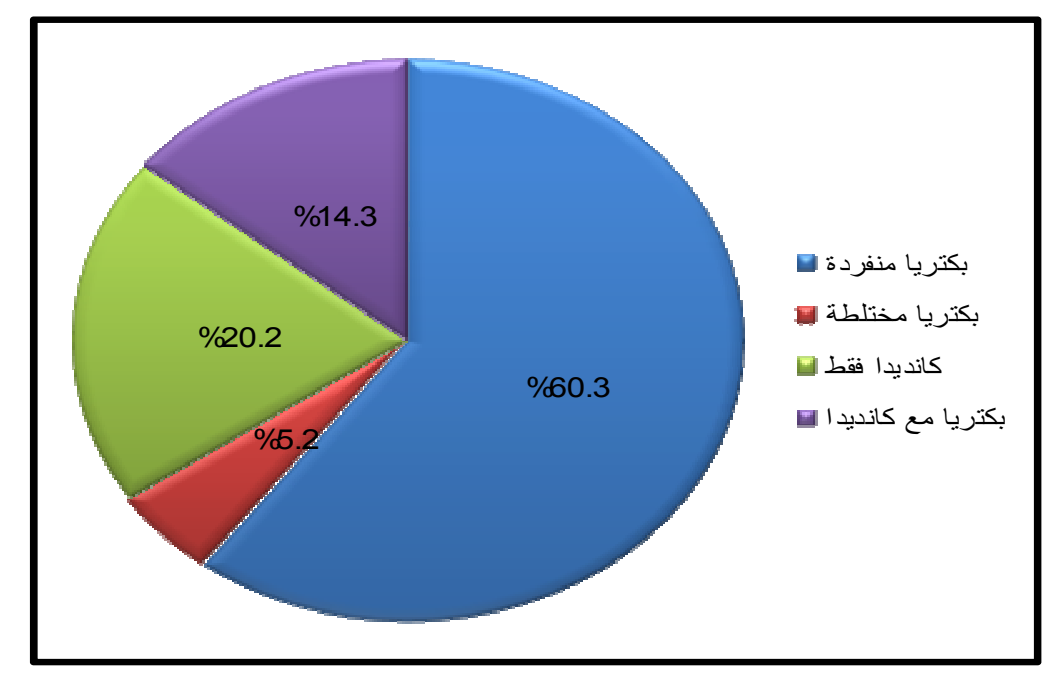

\section{الشثل 2: النب المئوية لامجامبع الجرثومية المعزولة والمشخصة في الدرلسة الحالية}

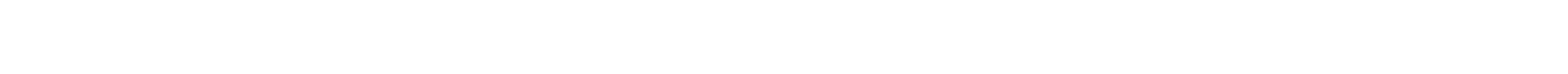

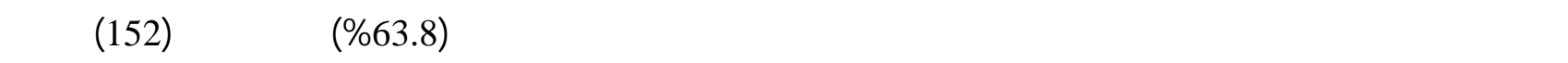
شكلت الجراثيمسالبة الصبغة نسبة (36.2\%)شكل (3)، وهذه النتائج لا تقفق مع نتائج درلسة البلحثتين الجمالي والغريري فيسنة

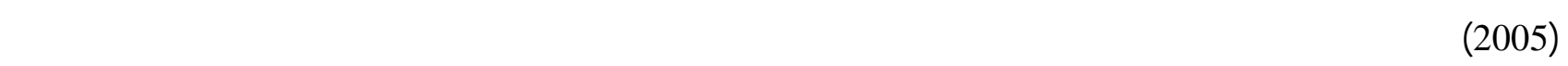


المهبلية، بينما ظاقتت هذه النتائج مع نتائج البلمث Razzak et al., النين وجدوا أن نسبة البكتريا الموجب ـة لل ـصبغة أعلى (66.2\%) من البكتريا للسالبة الصبغة (44.8\%) من مجموع (130) عينة.

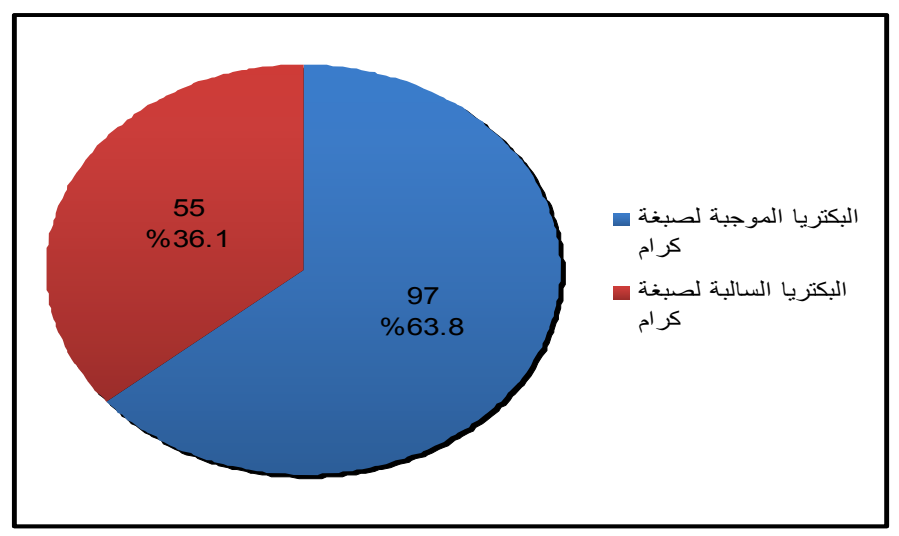

\section{الثكل 3: لأعداد والنسب المئوبة للبكنربا الموجبة وللسالبة لصبغةكرله المعزولة بصورةمفرةفي الدرلسة الحالية}

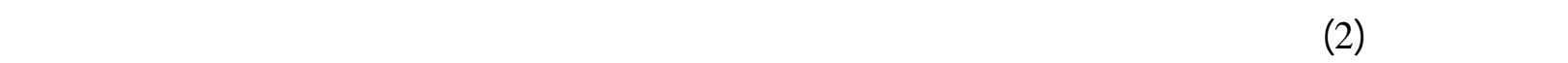

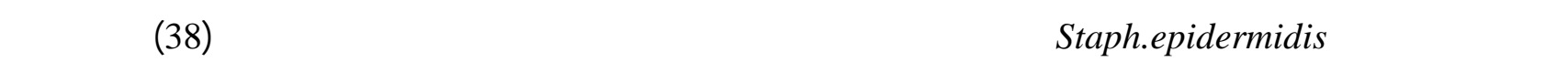

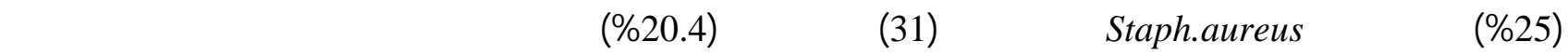
Strep. pyogenes

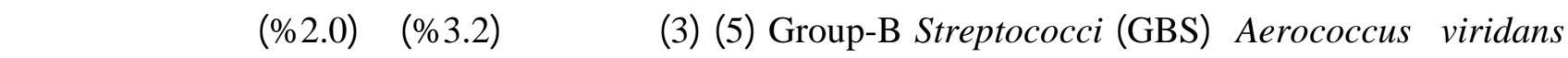

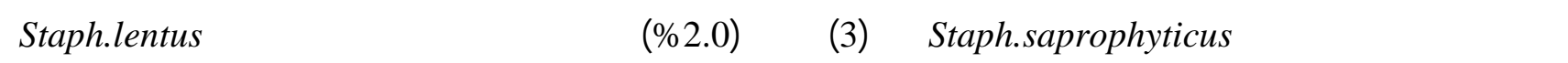
Actinomyces ،Staph.heamolyticus

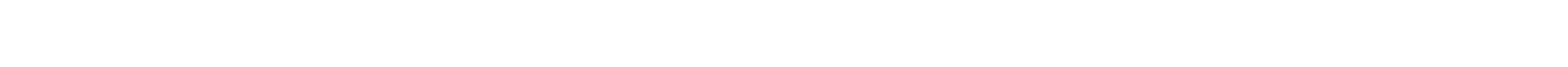
البكتيري هي البكتريا للسالبة لاختبار التجط والمتمثلة بجرثومة Staph.epidermidis وهذه النتيجة تتفق مع الدرلسة المحلية الني قلمت بها البلحثة للسطلن فيسنة (2001) والتي وجدت في درلستها بأن أعلى نسبة للجرالثيم المحثة لالتهابلت المهل البكتي -ري

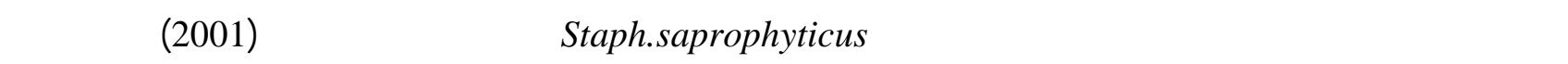
جراثيم GBS شكلت أعلى نسبة (18.2\%) من مجموع (220) عينة وهذه النتيجة لم تشظاق مع ما توصلت إليه درلمتنا إذشكلت هذه الجراثيم (2.0\%) من مجموع العزلات.

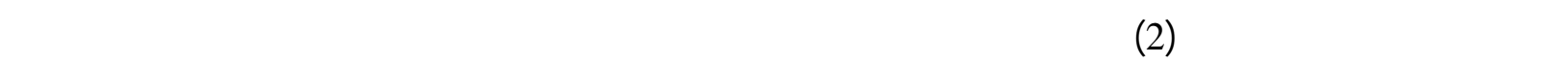

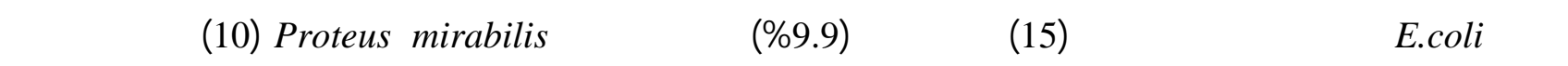

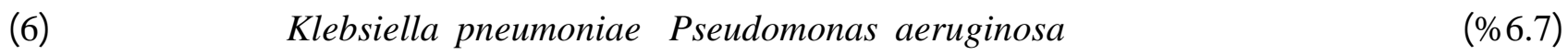




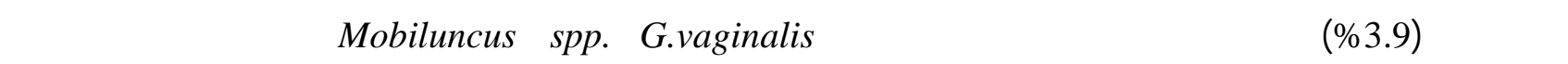

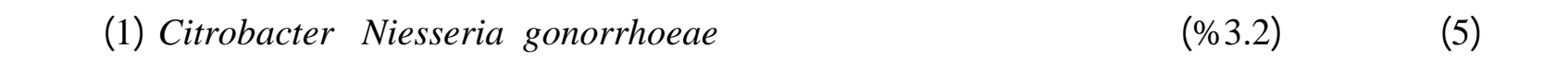

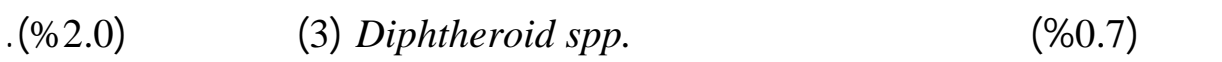

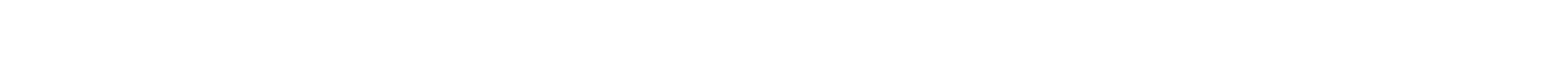
E.coli

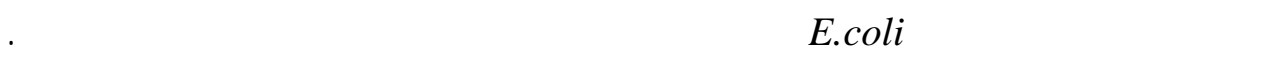

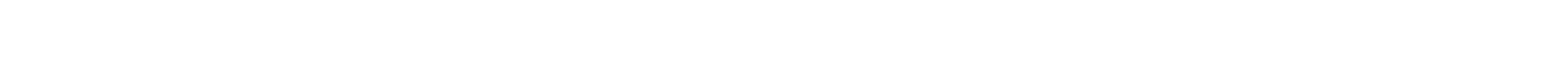

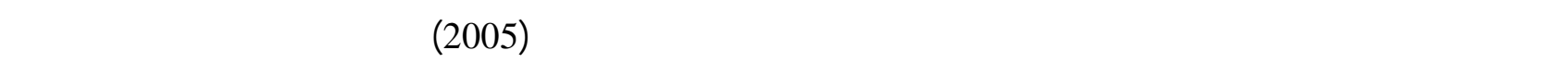

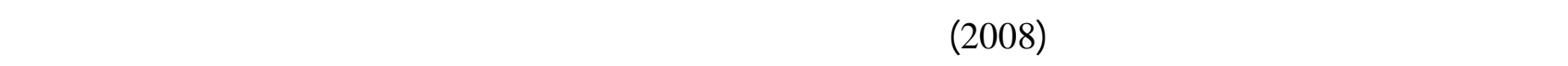

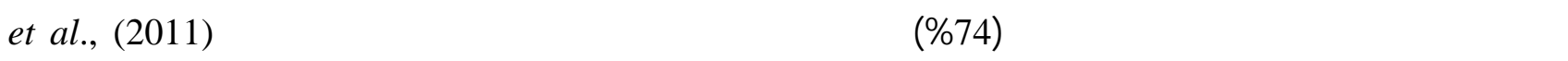

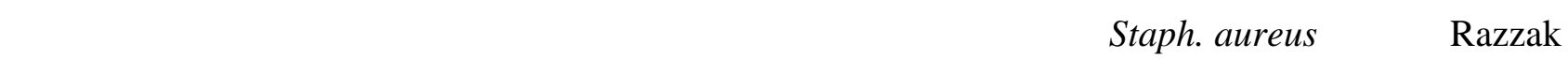

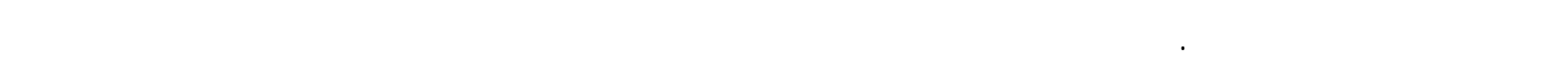

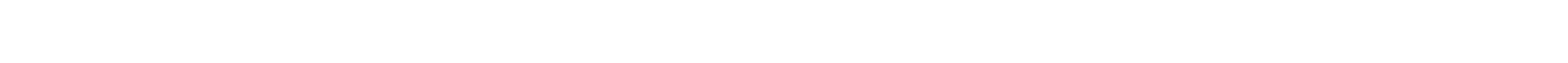
خهشاً في الجلد مسببة الالتهابلت المهبلية (Perry and Staley, 1997).

\section{الجدط 2: الأعداد والنب المئوبة لأنواع البكنربا الموجبة وللسالبة لصبغةكرله والتيظهرت بشكل مفردف الدرلسة الحالية}

\begin{tabular}{|c|c|c|}
\hline \multirow{2}{*}{ النسبة\%\% } & \multirow{2}{*}{ 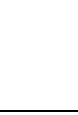 } & نوع العزلة البكنيربة \\
\hline & & البكتربا الموجبة لصبغة كرلم \\
\hline 25 & 38 & Staph.epidermidis \\
\hline 20.4 & 31 & Staph.aureus \\
\hline 2.0 & 3 & Staph.saprophytics \\
\hline 0.7 & 1 & Staph.lentus \\
\hline 0.7 & 1 & Staph.haemolyticus \\
\hline 3.9 & 6 & Streptococcus pyogenes \\
\hline 2.0 & 3 & (GBS)Group-B Streptococci \\
\hline 0.7 & 1 & Actimomyces \\
\hline 3.9 & 6 & Listeria spp. \\
\hline 3.2 & 5 & Aerococcus viridians \\
\hline \multirow[t]{2}{*}{1.3} & 2 & Gemella haemolysans \\
\hline & & البكنربا اللسالبة لصبغةكرله \\
\hline 9.9 & 15 & E.coli \\
\hline 6.7 & 10 & Proteus mirabilis \\
\hline 3.2 & 5 & Gardnerella vaginalis \\
\hline 3.2 & 5 & Mobiluncus spp. \\
\hline 0.7 & 1 & Niesseria gonorrhoeae \\
\hline 2.0 & 3 & Diphtheroid spp. \\
\hline 3.9 & 6 & Klebsiella pneumoniae \\
\hline 2.0 & 3 & Serratia odorifera \\
\hline 0.7 & 1 & Citrobacter spp. \\
\hline 3.9 & 6 & Pseudomonas aeruginosa \\
\hline$\% 100$ & 152 & Total \\
\hline
\end{tabular}




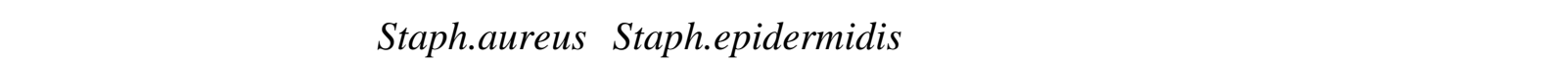

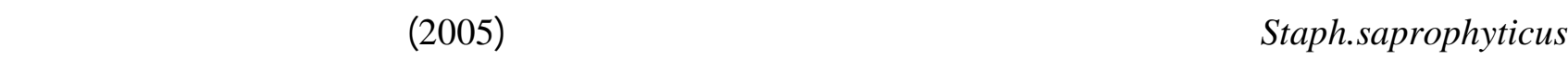
Staph.saprophyticus تسود في المسحت المهبلية على Staureus ،Staph.epidermidis إن للسب في ظهور لختلاف في نسب الجراثيم المعزولة في الدرلست المختلفة قد يعود إلى عوالمل عديدة منه L لخ ـتلاف

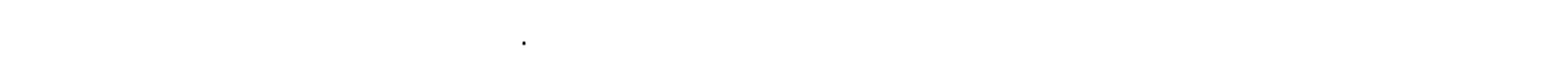

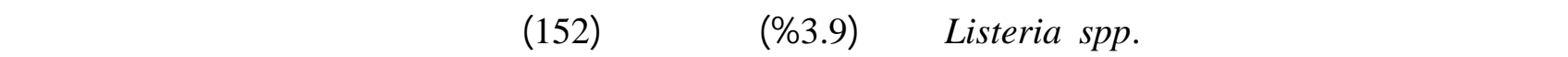
مهبل النساء الحولمل اللولتي يعانين من الإبقلط المتكرر Repeated abortion. عزلت جرثومة (GBS ) بصورة مفررة وبنسبة (2.0\%) وهي نسبة قليلة جداً مقارنة مع نسبتها في درلسة اللسليم (2001)

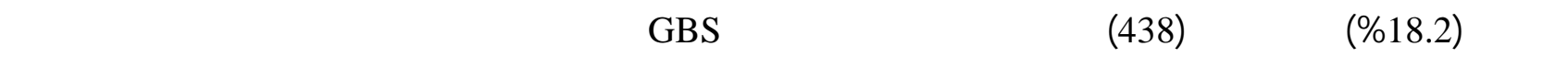

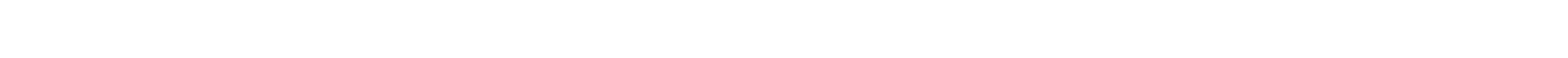

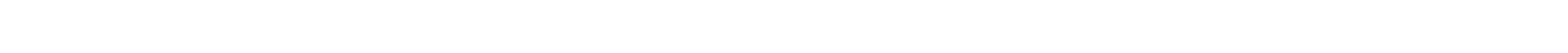

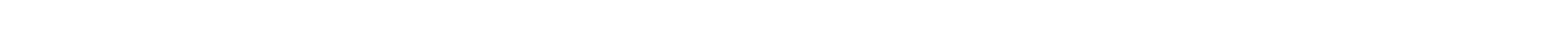
حلمض اللكتيك، فضلاً عن كونها تعد من الجرالثيم التي تنقل جنسياً، العلمل الذي يساعد على زياة نسبة تولج دها ف ي المهب لل .(Lener, 1977; Feikin et al., 2001) كما تضمنت الدرلسة بعض الحالات التي عزلت فيها أنواع بكتيريةظهرت بشكل مختط كما في الجدول (3) الذي يوض حمانح

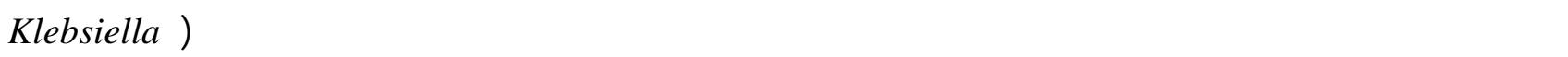
(pneumoniae + Staph.epidermidis (Staph.epidenmidis + E.coli) لقية الجراثيم التي ظهرت بشكل مختلط وأيضا ت ساوت ن سبة جرث -ومتي (Staph.aureus+ Strep.pyogenes) وجرث -ومتي

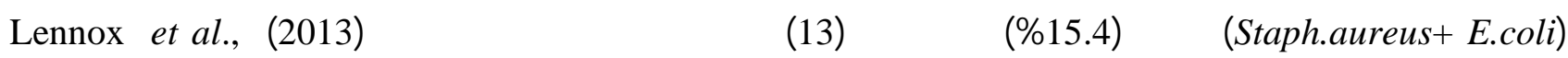
Razzak et al., إلى وجود عزلات مختلطة عند درلسته لالتهلب المهل البكتيري والنطري بين النساء. كما وجد البلهث (2011)

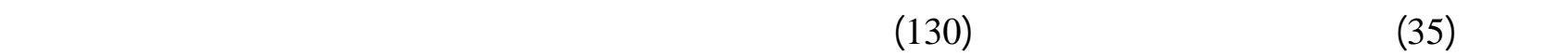

\section{الجطل 3: الأعداد والنسب المئوبة لأنولع البكتربا الموجبة وللسالبة لصبغةكرلم التيظهرت بشكلمختلافي الدرلسة الحالية}

\begin{tabular}{|c|c|c|}
\hline$\%$ & العد & ل ل لواع البكتربا \\
\hline 30.8 & 4 & Staph.epidermidis + E.coli \\
\hline 15.4 & 2 & Staph.aureus+ Strep.pyogenes \\
\hline 7.6 & 1 & Klebsiella pneumonia + Staph.epidermidis \\
\hline 15.4 & 2 & Staph.aureus + E.coli \\
\hline 30.4 & 4 & Staph.aureus+ Proteus.mirabilis \\
\hline 100 & 13 & Total \\
\hline
\end{tabular}


لظٔلهرت درلستناسيادة واضحة في تولجد الخمائر والمتمثلة بخميرة C.albicans والتي ظهرت بشكل مفرد وكانت ع دد

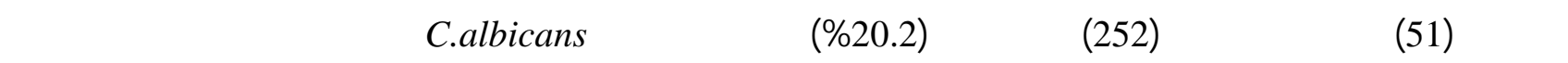
البكتريا المهبلية المعزولة قيد الدرلسة جدول (4)، انشكلت هذ الخميرة مع البكتريا المعوية E.coli أعلى نسبة إذ بلغت (27.8\%) من مجموع (36) عزلة مختلطة فيما لظهرت هذه الخميرة مع بكتريا Staph.epidermidis, و Staph.aureus نسبة مت ساوية الخدية

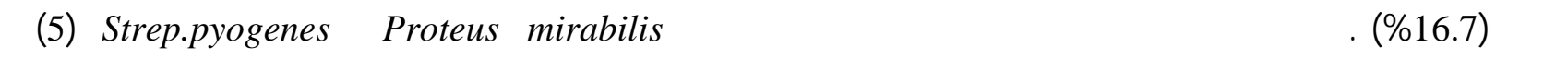

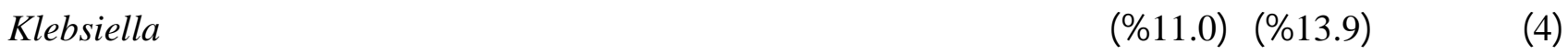

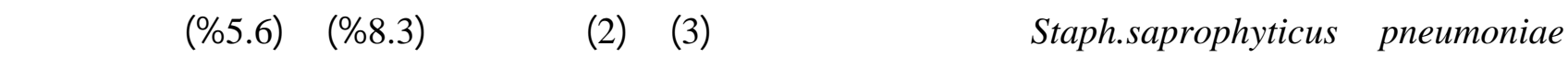
من مجموع (36) عزلة مختلطة، وقد وجد البلمث (2013) Sزلات مختلطة بين البكتري ا والفطري الت ف مي درلسته لانتشار الالتهابلت المهبلية بين النساء الحولمل.

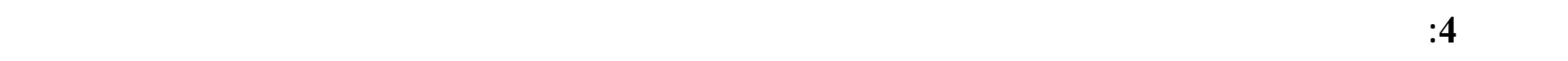 Candida albicans}

\begin{tabular}{|c|c|c|}
\hline$\%$ & العد & الكائن المجهري \\
\hline 27.8 & 10 & C.albicans + E.coli \\
\hline 16.7 & 6 & C.albicans + Staph.aureus \\
\hline 5.6 & 2 & C.albicans + Staph.saprophyticus \\
\hline 13.9 & 5 & C.albicans + Proteus mirabilis \\
\hline 8.3 & 3 & C.albicans + Klebsiella pneumonia \\
\hline 11 & 4 & C.albicans + Strep.pyogenes \\
\hline 16.7 & 6 & C.albicans + Staph.epidermidis \\
\hline 100 & 36 & $\begin{array}{ll}\text { Total } \\
\end{array}$ \\
\hline
\end{tabular}

إن تولجد الخمائر في الغشاء المخطي المطن للمه والقنة الهضمية والقنة التنلسلية البولية يعد كفلوراطبيعية، إلا أنها تع دـ

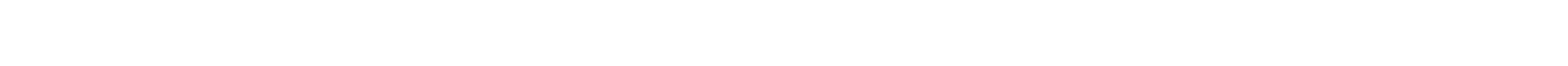
هذه الأملكن (Tortora et al., 1998).

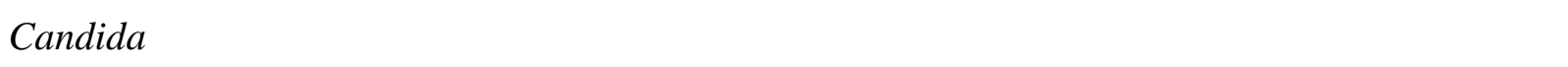
albicans

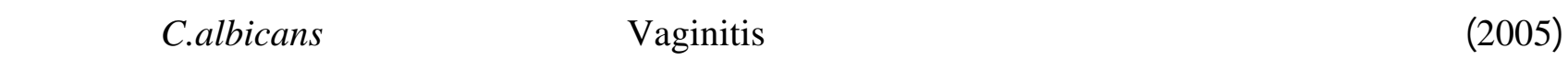

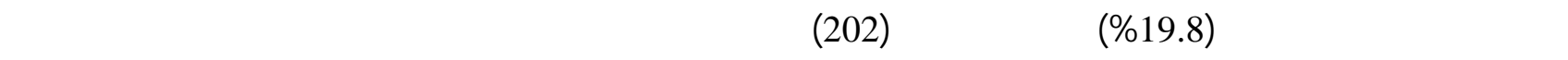
Razzak et al., (2011) وتجدر الإثارة إلى عدم ملاحظة الطفيلي Trichomonas vaginalis في أي من العينت المختبرة خلل الفحص الأول مي 


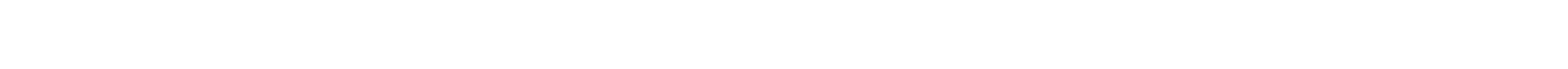

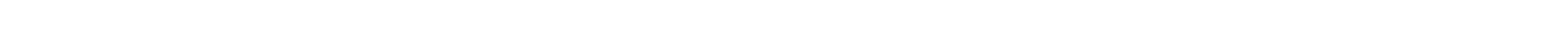

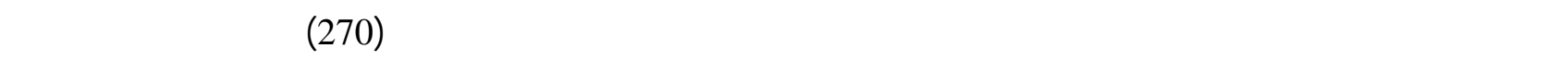

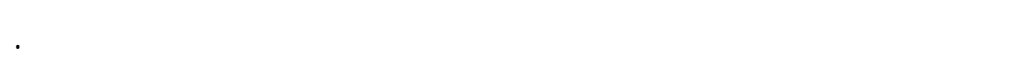

الملافة بين الممر والإصلبك المدروسة لمستبيلة تراومت أعمار النساء التيشملتها الدرلسة ما بين (20 - 72)سنة وتبين من خلال نتائج الدرلسة الموضحة في الجدول رقم (5) ارقفاعَ في نسبة الإصابة بالاخماج التنلسلية لدى النساء في العمر بين 20 و 50سنة والنخفاضاً في نسبة الإصابلت لدى النساء

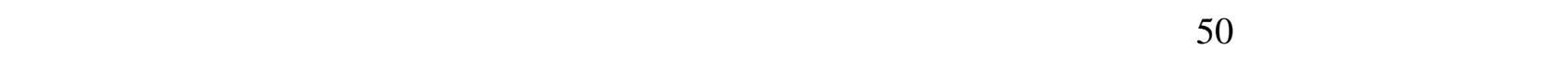

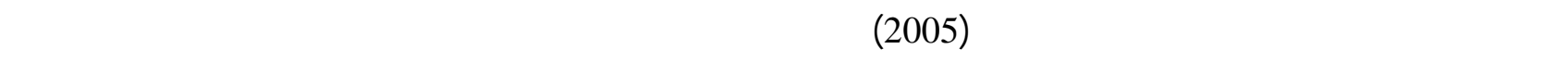

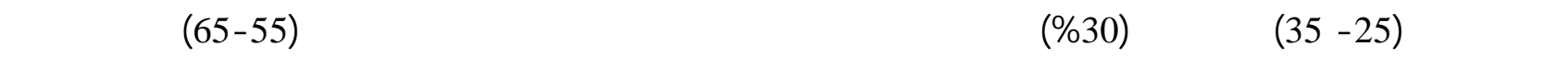

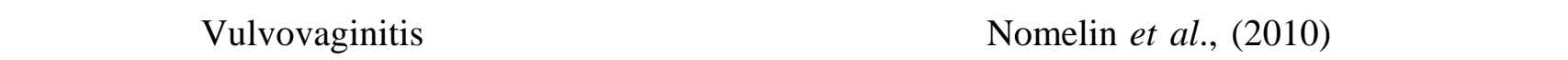

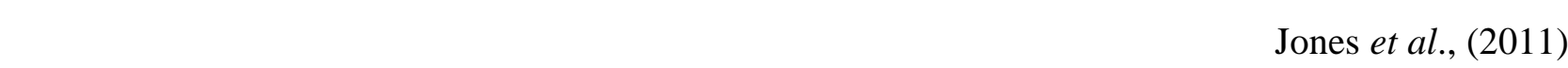
علاقة بين عمر المرأة وبين هذه الإصابت. لئشارت درلسة (Acikgoz et al., 2002) ان العمر لحد العولمل المسؤولة عن تغاير الفلورا الطبيعية للمهبل ويسببظهور دوري لبعض الأحياء المجهرية الممرضة، وان ارتفاع نسبة الإصابت عند النساء فيسن الإنجلب وعند الفئنين (20 -29)س نة و و

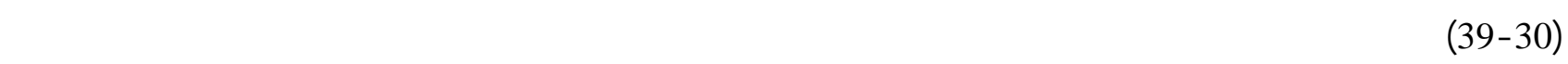

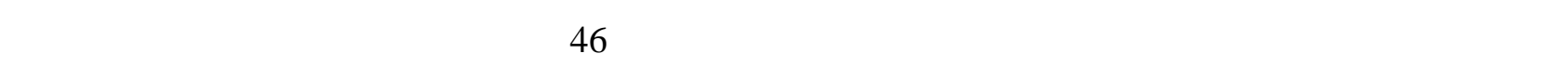
الهيدروجيني (pH) إلى الحلمضية المنغفضة (العاني، 2005).

\section{الملافة بين الحطل والصلبلت المدروسة}

بينت النتائج الموضحة في الجدول (5) لن التهلب المهل البكتيري يحدث عند النساء غير الحولمل ن سبة اعل م مقارن ـة

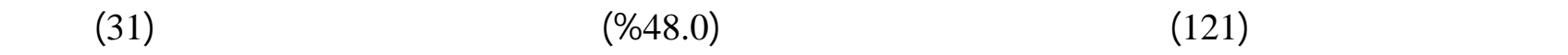
عند النساء الحولمل أي بنسبة (12.3\%). أما الالتهلب الفطري فقشكل عند النساء الحولمل نسبة أعلى مقارنة بغير الحولمل اذ كانت (33) حالة عند النساء الحولمل

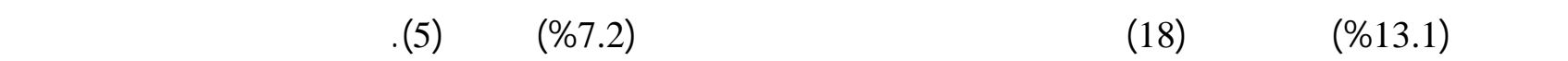

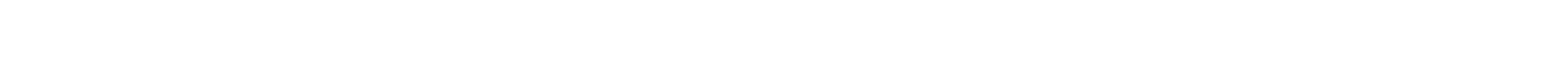

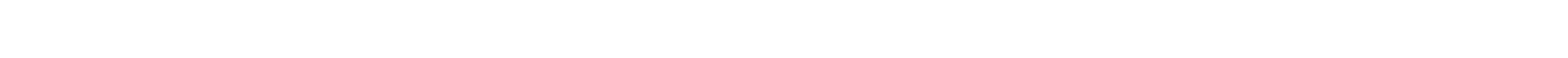

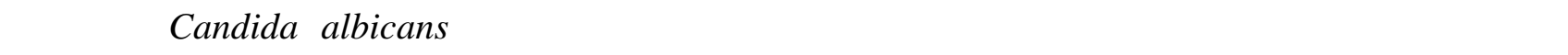
Candida albicans _ _ (Mahdi and Al-Hamdani, 1998)

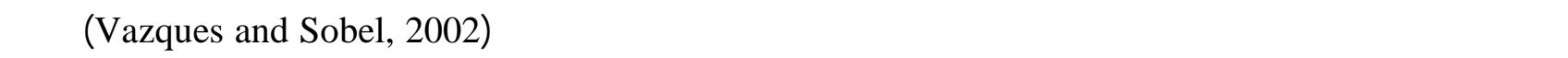

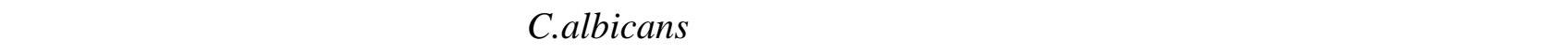


الحمل التي تعلل على ترسيب الكلايكوجين في الخلايا الطالئية للمهل مما ينتج عنه النخاض في الاس الهيدروجيني للمهبل ويجعله بيئة ملائمة لنمو الخميرة أو قد يعود للسب إلى الإفرلط في تتاول المضادات الحيوية التي تساهم في قل الأحياء المجهرية الطبيعية في الجسم مما يشجع لستيطان المبيضلت في المهل (De-leon et al., 2002). أما فيما يخص عالل عددمرك الحطل وعلفته بالإصلبة التنلسلية عند المرأة فقد كثفت نتائج الدرلسة الحالي ـة ح ص صول الإصابلت في (56.6\%) من النساء اللواتي لديهن حمل متكرر (3-5) مرات هن لكثر عرضة للإصابة بالالتهلبك المهبلية. وهذا ما

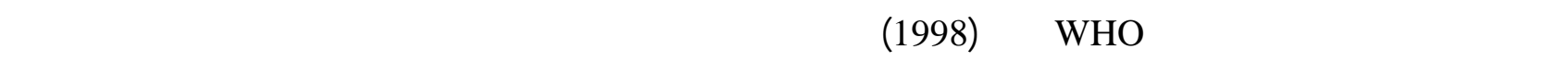

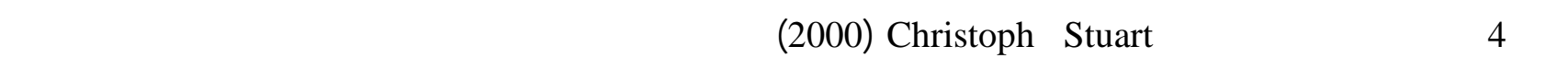

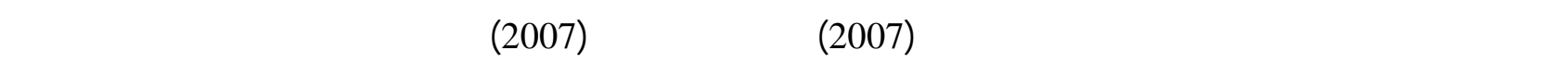
عدد مررت الحمل وإمكانية الإصابة بالتهل المهل الجرثومي، كما لوظ من خلل درلسة علاقة تكرار الحمل مع حدوث الإصابة

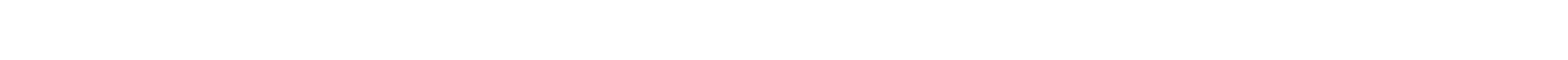
النساء اللواتي يسكن المدينة.

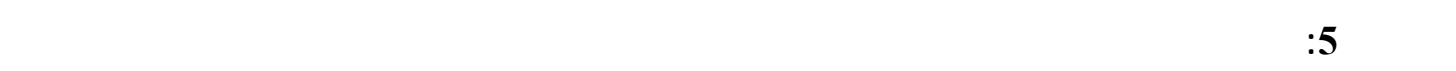

\begin{tabular}{|c|c|c|c|c|c|c|c|}
\hline \multirow{3}{*}{ \% الكلية } & \multicolumn{6}{|c|}{ Vaginitis التهل المهل } & \multirow{3}{*}{ عولل الطلورة } \\
\hline & \multicolumn{2}{|c|}{ المختلا } & \multicolumn{2}{|c|}{ الفلري } & \multicolumn{2}{|c|}{ البكتيري } & \\
\hline & $\%$ & العد & $\%$ & العد & $\%$ & العدد & \\
\hline & & & & & & & العمر \\
\hline 93.5 & 19.4 & 49 & 18.3 & 46 & 55.6 & 140 & الل من 50سنة \\
\hline \multirow[t]{2}{*}{6.7} & 0 & 0 & 1.9 & 5 & 4.8 & 12 & لكثر من 50سنة \\
\hline & & & & & & & الحطل \\
\hline 33.3 & 7.9 & 20 & 13.1 & 33 & 12.3 & 31 & الحوالمل ل \\
\hline \multirow[t]{2}{*}{66.7} & 11.5 & 29 & 7.2 & 18 & 48.0 & 121 & غير الحولال \\
\hline & & & & & & & الامراض الاخرى \\
\hline 43.1 & 8.7 & 22 & 7.1 & 18 & 27.3 & 69 & التهابت المجاري البولية \\
\hline \multirow{2}{*}{15} & 0 & 0 & 8.7 & 22 & 6.3 & 16 & ل للسكري \\
\hline & & & & & & & وسالل منع الحطل \\
\hline 32.8 & 3.5 & 9 & 9.9 & 25 & 19.4 & 49 & ادوت \\
\hline 3 & 0 & 0 & 0.3 & 1 & 2.7 & 7 & حبوب \\
\hline 56.6 & 3.5 & 9 & 18.2 & 46 & 34.9 & 88 & عددمرات الحمل \\
\hline \multirow[t]{2}{*}{13.7} & 1.9 & 5 & 3.5 & 9 & 8.3 & 21 & عدد الاسقطلت \\
\hline & & & & & & & الحالة الاجتماعية \\
\hline \multirow[t]{2}{*}{100} & 19.5 & 49 & 20.2 & 51 & 60.3 & 152 & متزوجة \\
\hline & - & - & - & - & - & - & عازبة \\
\hline
\end{tabular}




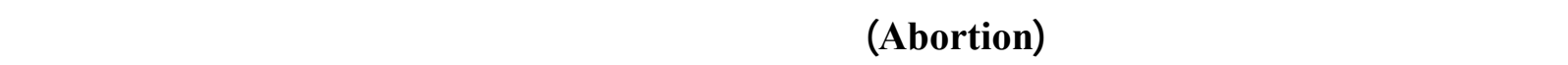

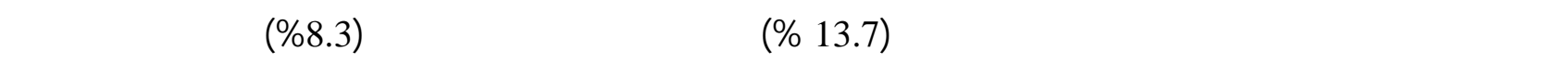

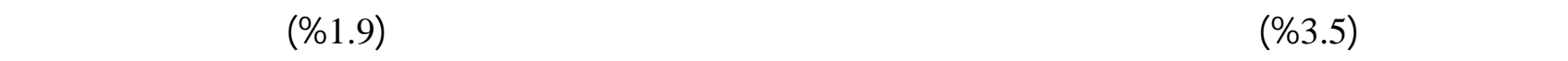

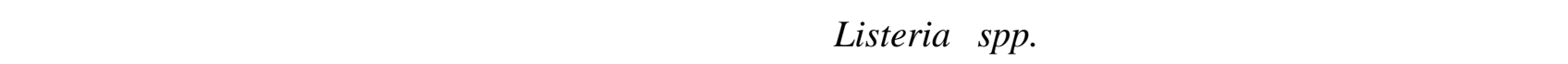

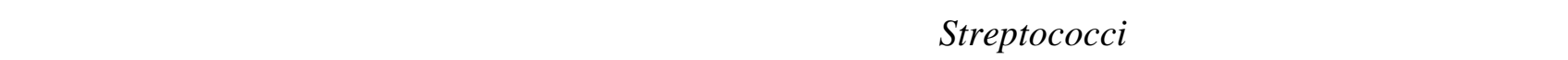

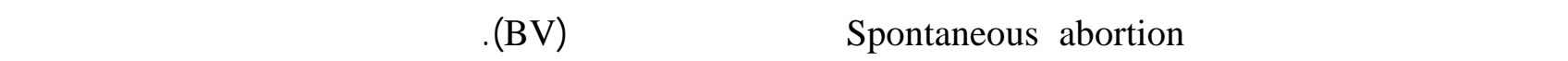

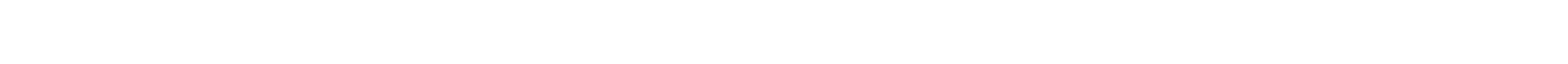

البولية (Reeder et al., 1997).

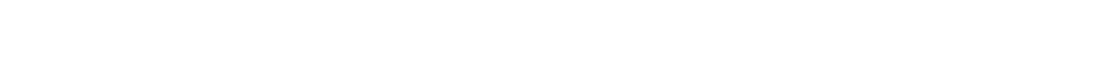

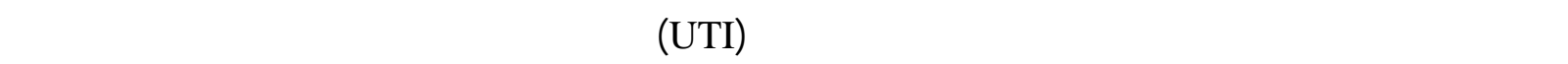

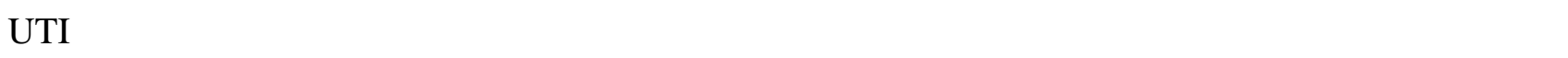

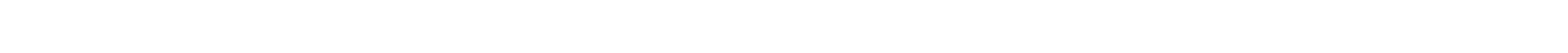

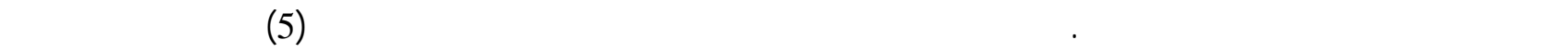

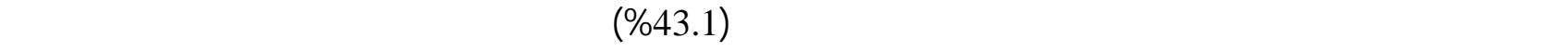

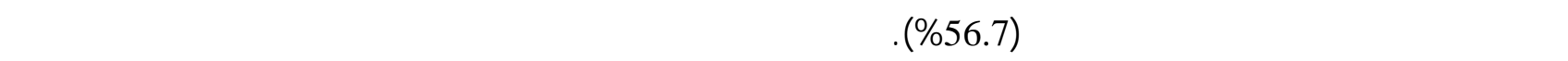

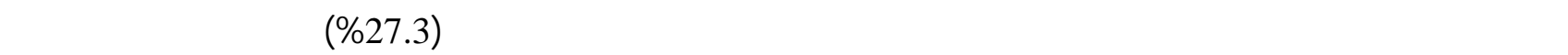

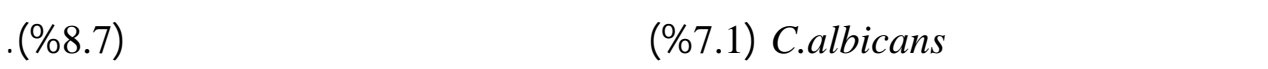

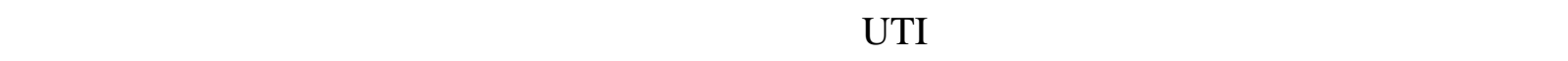

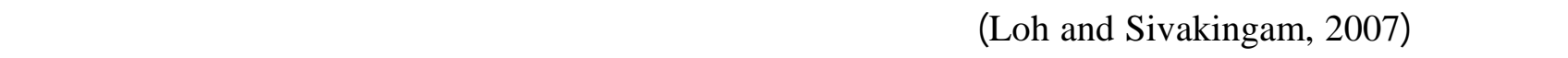

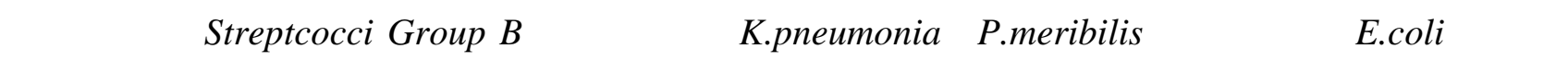
الأكثرشيوعاً لدى النساء الحوالم تنليها .Staphylococcus spp.

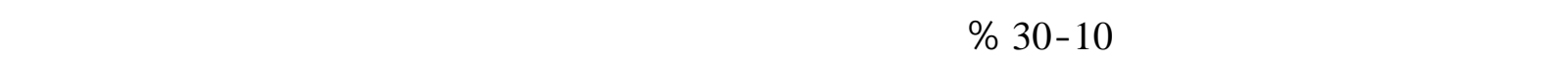

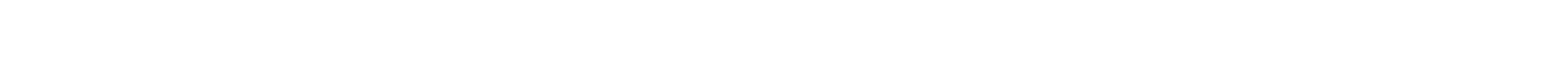

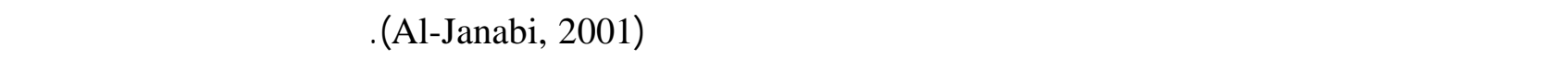

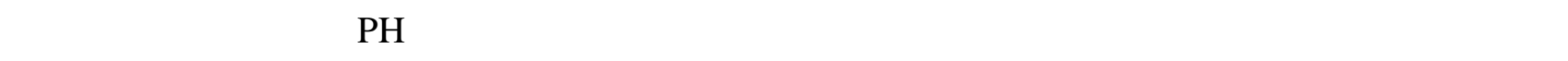

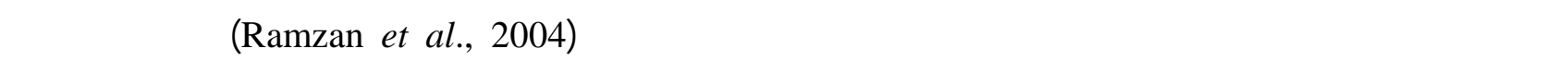

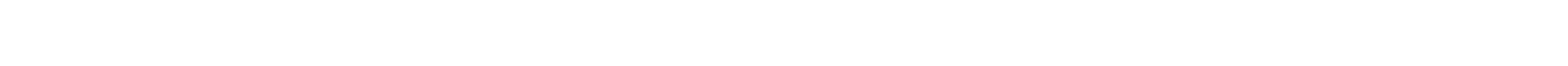

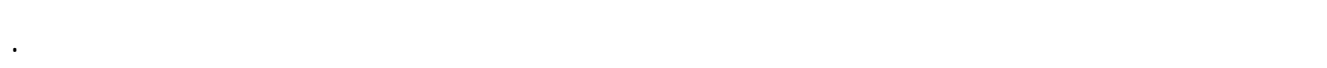


فليحة حبيب هسين ومهن أيوب عيسى

لما فيما يخص دور عللم مرض المكر Diabetes في حدوث الإصلبة التنلسلية، فيوضح الجدول (5) أن سبة الإصابة

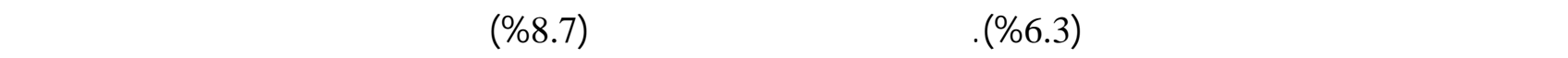

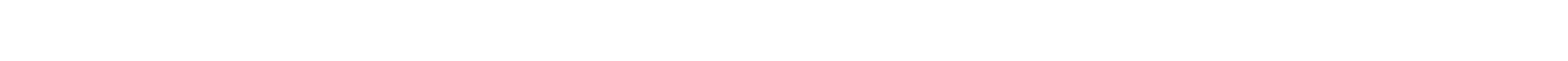

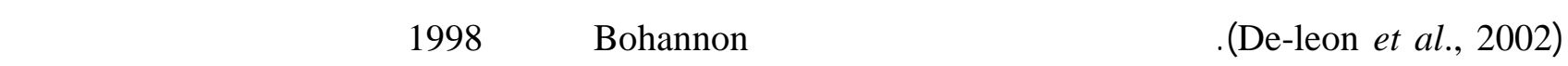
الفرجي الفرري Vulvovaginal candida infection بين النساء المصابت بمرض للسكري أعله من النساء غير الم صابلت

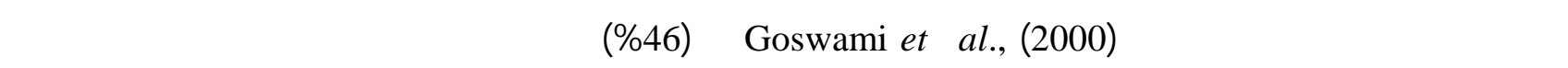
المهل لحد أنواع جنس المبيضلت بالمقارنة مع (23\%) من النساء غير المصابكت بلمأسكري.

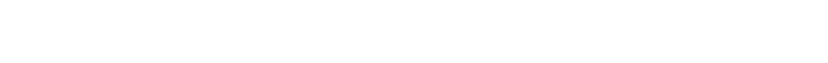

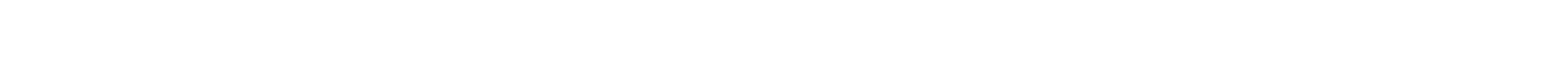
درلستنا هذه كلت لستعمل اللولب (IUD) هو للشائع بين النساء قيد الدرلسة لمنع الحل، وبينت نتائج الدرلسة ان اغل يب الذ ساء

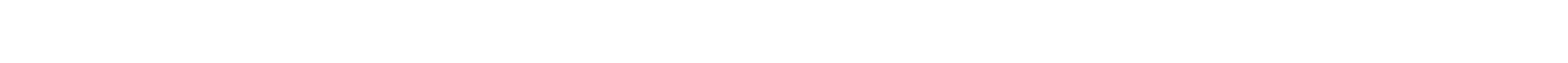

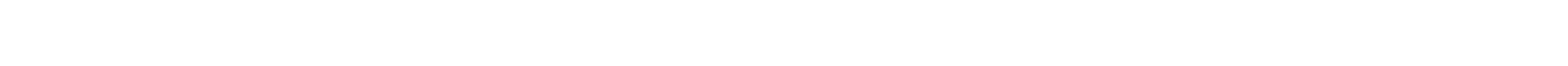

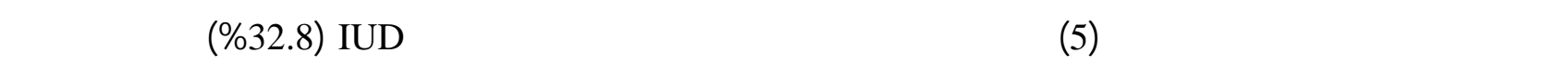
بالتهابلت بكتيرية وظطية ولخرى مختلطة.

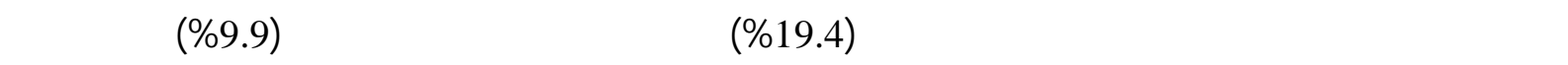

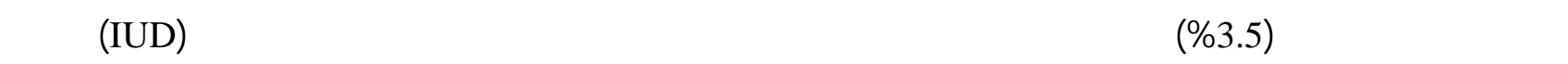

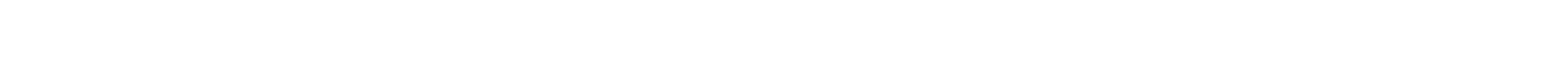

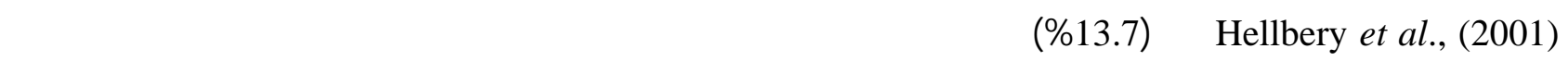

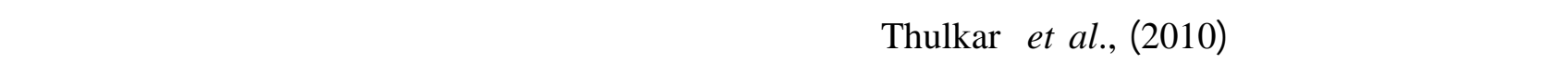

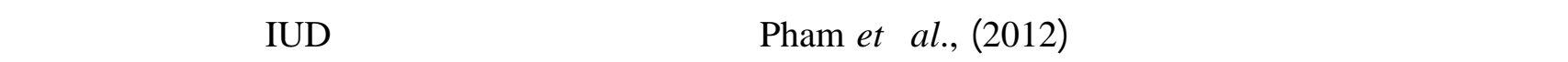
المهبلية الجرثومية ولا تعد الإصابة الناتجة عن لستخدلم موانع الحمل هذه ضنمن الإصابلت المتقلة جنسياً.

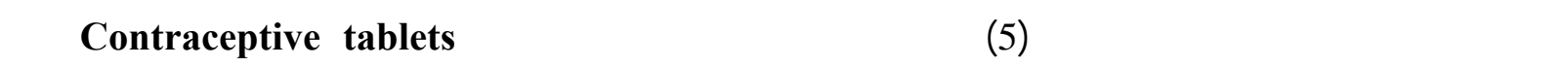

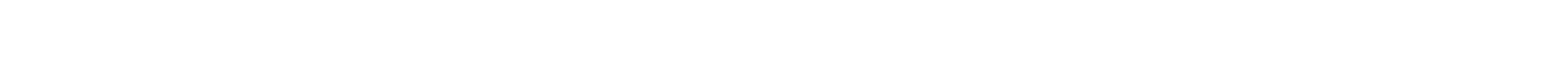

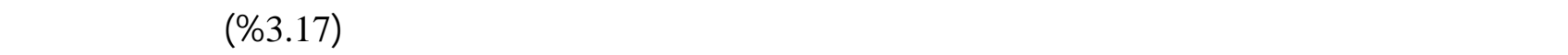

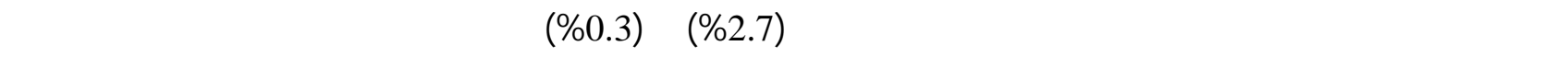

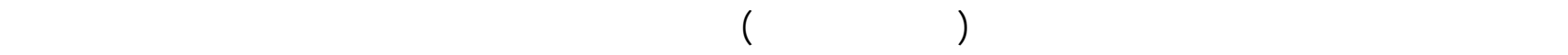

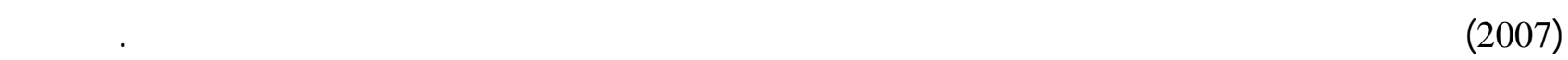

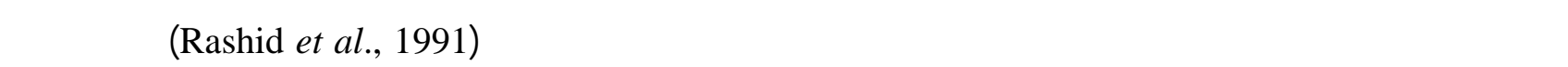

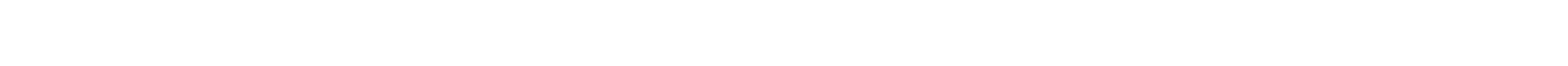

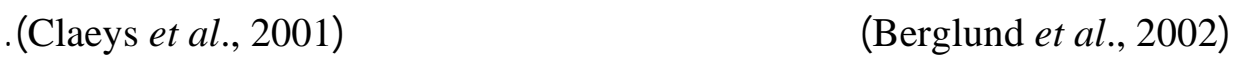


تثشير نتائجنا إلى وجود علاقة بين المطقة التي تسكنها النساء ولمكانية إصابتهن بالتهلب المهل حيث بلغت ذ سبة الذ ساء المصابلت بالالتهابت المهبلية واللوالتي يقطن الرف (59.2\%) بينما بلغت نسبة النساء اللوالتي يقطن المدينة (40.8\%) بالتالي ف فالن

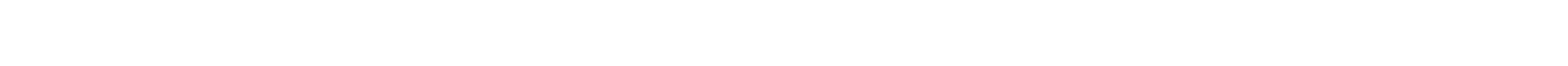

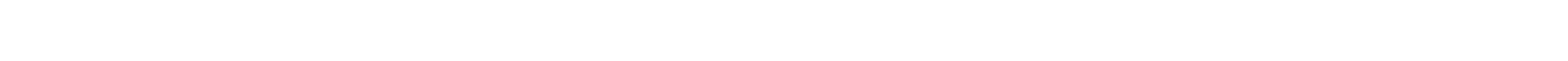
الإصابك. ولخيراً لم تتمكن الدرلسة الحالية من إثبات وجود علاقة بين نوع العمل الذي تماسسه النساء قيد الدرلسة والإصابة بالاخماج

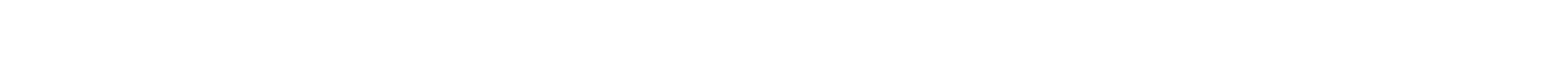
الدرلسة كن من المتزوجلت.

\section{المصاكر العربية}

البيلتي، ايملن نطلق نلجي (2004). التدلل البكتيري مع عولمل ضراوة خميرة الكاننيدا المسبة لحالات التهلب الفرج والمهب لـ. لطاروحة لكتوره، كلية العلوم، الجلمعة المستنصرية.

الجمالم، مدركة محمود هشن العليوي (2005). التهلب المجاري البولية التنلسلية لدى نساء مدينة الموصل. بسالة ملجستير، كلية العلوم، جلمعة الموصل.

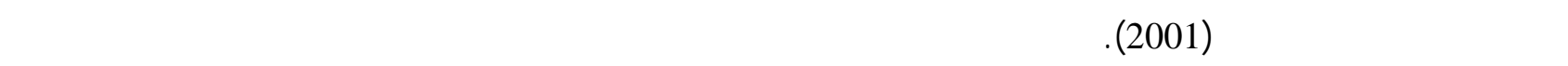
اللسيل البولي لدى الإنلث فيسن النضوج بمدينة الموصل. بسالة ملجستير، كلية العلوم، جلمعة الموصل.

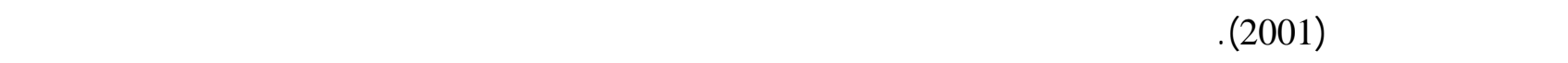
Streptococcus agaluclia (GBS) بسالة ملجستير، كلية العلوم، جلمعة الموصل، العراق. اللسليم،سحر لقمان (2010). عزل وتشخيص الكتينومليسينت في النساء الحولمل في مدينة الموصل.مجلة أبحلث كلية التربيـة الأسلسية. 10(2)، 521 -529.

العالي، زينة هلثمشهاب (2005). درلسة وبائية فصلية للإصابت المهبلية في بغداد. بسالة ملجستير، كلية التربية، جلمعة بغداد.

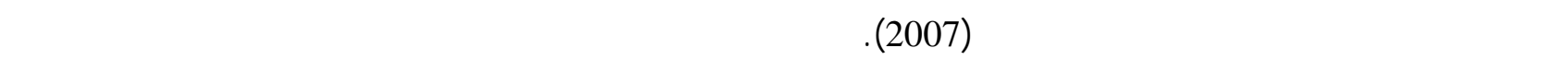
المهل الفطري لدى النساء للسوريك، مجلة جلمعة دشق للعلوم الصحية. 23(1)، 2007)، 239 -249.

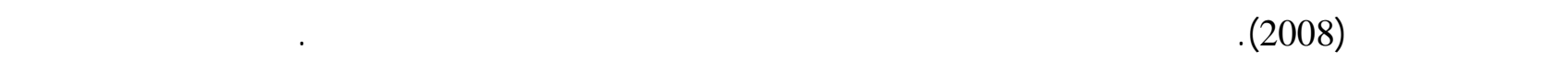
للعلوم الصرفة، (2)، 8 -13. الغريري، لُٔسماء زكيشيتاوي (2005). التحري عن البراعم الحشففية والجراثيم الأخرى في خمج الجهاز التنلسلي لدى الذساء.

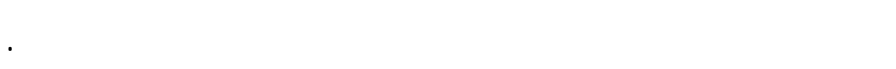




$$
\text { فليحة حبيب مسين ومRت أيوب عيسى }
$$

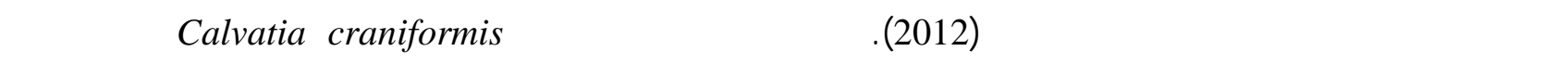

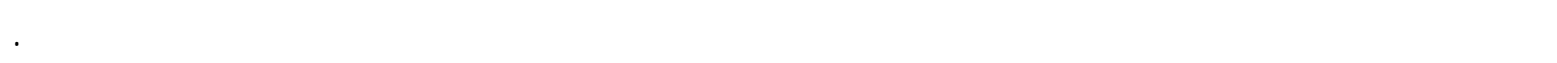
مجلة دياله للعلوم الزراعية، 4(2)، 1 -10.

معروف، محمد (2007). العصيت المسؤولة عن التهلب المهل لدى النساء المتزوجلت والعولمل المؤهبة له. مجل ـة الت شخيص المختبري. $4(4)$ (4)، 3 -14.

\section{المصادر الأجنبية}

Acikgoz, Z.C.; Ozturk, T.N.; Gamberzad, S.; Ark, E.; Gocer, S. (2002). Retrospective Microbiology evaluation of Vaginal Cutures. Mikrobiol. Bul., 26(1), 23-9.

Al-Janabi, L.A.K. (2001). Chlamydia and other sexually Transmitted pathogens, Microbiological and serological prospective study in Baghdad women, Al- Mustansiriya, a thesis of Master Microbiology.

Atlas, R.M. (2006). "Handbook of Microbiological Media for the Examination of Food". $2^{\text {nd }}$ ed. Taylor and Francis Group. LLC, USA.

Berglund, A.L.; Nigard, L.; Rylander, E. (2002). Vulvar pain, sexual behavior and genital infections in young population: apilot study. Acta obstet Gynecol scand., 81(8), 738-42.

Bohannon, J.V. (1998). Treatment of Vulvovaginal candidiasis on patients with Diabetes. Diabetes care., 21(3), 451-456.

Braunwald, F.; Fauci, A.; Kasper, E.; Hauser, C.; Longo, W.; Jameson, B. (2001). "Harrison's Principles of Internal Medicine". 15 ${ }^{\text {th }}$ ed., Vol. 3, London., pp. 1620-1626.

Brooks, G.; Butel, J.; Morse, S.(1998). "Medical Microbiology". $21^{\text {st }}$ ed. Printed in Lebanon., pp. 235340.

Claeys, P.; Ismailov, R.; Rathe, S.; Jabbarova, A.; Clay, G.; Fonck, K.; Temmermain, M. (2001) Sexually transmitted infection and reproductive health in Azerbiajan. Sex transm, Dis., 28(7), 372- 378.

Collee, J.G.; Fraser, A.G.; Marimon, B.P.; Simmons, A. (1996). "Mackie and McCartney Practical Medical Microbiology". $4^{\text {th }}$ ed. Churchill living stone, Edinburgh, UK.

Curran, T. (2010). Bacterial Vaginosis. Medicine., 22(4), 28-33.

De- leon, E.M.; Jacobers, S.J.; Sobel, J.D.; Foxman, B. (2002). Prevalence and risck factors for vaginal vandida colonization in women with typ. land 2 diabetes. BMC. Infect. Dis., 17(2), 1-11.

Feikin, D.R.; Thorsen, P.; Zywick, S.; Arpi, M.; Westergaard, J.G.; Schuchat, A. (2001). Association between colonization with group B streptococci during pregnancy and preterm delivery among Danish Women. Am. J. Obstet. Gynecol., 184(4), 427-433.

Forbes, B.A.; Sahm, D.F.; Wiessfeld, A.S. (2007). "Bailey and Sott's Diagnostic Microbiology". $12^{\text {th }}$ ed., Mosby, Esevier, Inc., U.S.A. P. 710.

Goswami, R.; Dadhwal, V.; Tejaswi, S.; Datta, K.; Paul. A.; Haricharan, RN.; Banerjee, U.; Koehupillai, NP. (2000). Species- Specific prevalence of Vaginal Candidiasis among patients with diabetes mellitus and its relation to their glycaemic status. J. Infect., 41(2), 162-6.

Hainer, B.L.; Gibson, MV. (2011). Vaginitis. Am Fam physician., 83(7), 807- 815.

Hellbery, D.; Nilsson, S.; Mardh, P.A. (2001). The diagnosis of bacterial vaginosis and vaginal flora changes. Arch. Gynecol. Obstet., 265(1), 11-15.

Hemalatha, R.; Romalaxmi, A.B.; Swetha, E.; Balakrishna, N.; Mastromarino, P.(2013). Evaluation of Vaginal PH. For detection of Bacterial Vaginosis India. J. Med. Res., 138(5), 354-359. 
Jones, S., Pollard, K.; Gomm, K.; Buckner, P. (2011). Antimicrobials vs. Homeopathic Remedies. Undergraduate Research J., 5(2), 20-25.

Koneman, E.W.; Allen, S.P.; Janda, W.C. (2006). "Color Atlas and Text Book of Diagnostic Microbiology". $6^{\text {th }}$ ed . Lippincott- willams and wilkins puplishers. Philadelphia, U.S.A.

Koumans, EH.; Sternberg, M.; Bruce, C. (2007). The prevalence of bacterial vaginosis in the united states, associations with symptoms, sexual behaviors, and reproductive health. Sex Transm Dis., 34, 864-9.

Lener, P.K.; Gopalala, K.E.; Wolinsky, M.D.; Jan, J.S. (1977). Group B. Streptococci (S. agalactiae) bacteria in adults. Midicin., 56, 457-473.

Lennox, J.A.; Abbey, S.P.; Udiba, D.; Mboto, C.I.; Ikpoh, I.S.; and Akubuenyi, F.C. (2013). Prevalence of Vaginitis and Vaginosis among university of Calabar female students. J. public Epidemipol. 5(4), 167-172.

Loh, K.Y.; Sivakingam, N. (2007). Urinary tract infection in pregnancy. Academy of Family Physicians of Malaysia, 2, (2).

Macfaddin, J.F.M. (1985). "Biochemical Test for Identification of Medical Bacteria". Williams and Willins. Baltimore. U.S.A.

Mahdi, N.K.; Al- Hamdani, M.M. (1998). Sexually transmitted diseases among women with habitual abortion East. Med. H. J., 4,343-349.

Masood, S.N.; Mumtaz, S.; Jahan, M. (2009). Pattern of normal vaginal flora in heathy married nonpregnant women. Pakistan J. Surgery. 25(2), 127-131.

NIAID, National Institute of Allergy an Infections Diseases ; (NIH), National Institute of Health (2003). Sexually Transmitted Diseases. http://www. Nia. Nih. Gov/.

Nomelini, R.S.; Carrijo, A.P.B.; Adad, S.J.; Nunes, A.A.; Murta, E.F.C. (2010). Relationship between infections agents for Vulvovaginitis and skin color. Sao Poulo Med. J. 128(6), 348-53.

Nugent, R.P.; Krhon, M.A.; Hillier, S.L. (1991). Realiabiltiy diagnosing bacterial vaginosis is improved by astandardized method of Gram stain interpretation. J. Clin. Microbiol., 2, 297301.

Perry, T.J.; Staley, J.T. (1997). "Microbiology and Dynamic". Printed in USA Library of congress.

Pham, T.N.D.; Kives, S.; Merovitz, L., Nitsch, R.; Tessler, K.; Yudin, M.H. (2012). Screening for bacterial vaginosis at the time of intrauterine contraceptive device insertion: Is there a role?. $J$. Obstet Gynaecol Can., 34(2), 179-185.

Quan, M. (2000). Vaginitis: meeting the clinical challenge. Clin. Cornevstone., 3(1), 36-47.

Ramzan, M.; Bakhsh, S.; Salem, A.; Khan, G.M.; Mustafa, G. (2004). Risk factors in urinary tract infection, Department of Pathology Women Medical Collage, Abbottabad Pakistan. Gomal J. Medical Sci. 2, 25-32.

Rashid, S.; Collins, M.; Kenned, R.J. (1991). A study of Candidiasis: the role fomites. Genitourin Med., 67(2), 137-42.

Razzak, M.S.A.; Al-Charrak, A.H.; Al-Greitty, B.H. (2011). Relationship between lactobacilli and apportunistic bacterial pathogens associated with Vaginitis. North. American J. Medical Sci. 3(4),185-192.

Reeder, S.; Martin, L.; Koniak, G. (1997). "Maternitynursing". $18^{\text {th }}$ ed., Lippincott, Philadelphia, New York. pp. 10-11. 


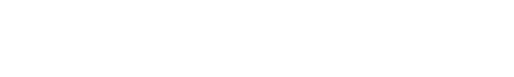

Shrestha, S.; Tuladhar, NR.; Basnyat, SA.; charya, GP.; Shrestha, P.; Kumar, P. (2013). Prevalence of vaginitis among pregnant women attending paropakar maternity and women's hospital, Thapathali, Kathmandu, Nepal. Nepal Med Coll. J. 13(4), 223-296.

Stuart, C. ; Christoph, L. (2000). " Obstetrics and Gynecology". $4^{\text {th }}$ ed, Arnold, London, 3 p.

Thulkar, J.; Kriplani, A.; Agarwal, N.; Vishnubhatla, S. (2010). Aetiology and risk factors of recurrent Vaginitis and its association with various contraceptive methods. Indian J. Med. Res. 131, 8387.

Tortora, G.H.; Funke, B.R.; Case, C.S. (1998). "Microbiology an Introduction". $6^{\text {th }}$ ed., Benjamin/ cummings publishing company. Menlopark, Califorinia., pp. 504-513.

Vazques, J.A.; Sobel, J.D. (2002). Mucosal Candidiasis Infect. Dis. Clin. N. Am., 16, 793-820.

WHO. (1998). "Healthy Workers Manual on Counseling for Maternal and Child Health". $2^{\text {nd }}$ ed., Manila, 14 p. 